\title{
Multiplicity of Research Programs in the Biological Systematics: a Case for Scientific Pluralism
}

\author{
Igor Pavlinov \\ Research Zoological Museum, Lomonosov Moscow State University, Bolshaya Nikitskaya 2, 125009 Moscow, \\ Russia
}

\begin{abstract}
Biological diversity (BD) explored by the biological systematics is a complexly organized natural phenomenon and can be partitioned in several aspects defined with references to various causal factors structuring biota. These BD aspects are studied by particular research programs based on specific taxonomic theories (TT). They provide in total a framework for comprehending the structure of the biological systematics and its multi-aspect relations to other fields of biology. General principles of individualizing BD aspects and construing TT as quasi-axiomatics are briefly considered. It stressed that each TT is characterized by a specific combination of interrelated ontological and epistemological premises most adequate to the BD aspect a TT deals with. The following contemporary research programs in systematics are recognized and characterized in brief: phenetic, rational (with several subprograms), numerical, typological (with several subprograms), biosystematic, biomorphic, phylogenetic (with several subprograms), evo-devo. From a scientific pluralism perspective, all these research programs related to particular naturally defined BD aspects are of the same biological and scientific significance and no one of them can pretend to take a privileged position. They elaborate "locally" natural classifications that can be united by a kind of generalized faceted classification.
\end{abstract}

Keywords: research program; taxonomic theory; phenetics; rational systematics; numerical systematics; typology; biosystematics; biomorphics; phylogenetics; evo-devo

\section{Introduction: Monism vs. pluralism}

All natural sciences deal with diversity of natural phenomena. The principal task of science in general is to puzzle this diversity out, to find ordering in it, and to represent this natural ordering in the form of generalizations that make up the content of the scientific knowledge. Such generalizations are of two general kinds - parametric and classificatory [1,2]. The parametric mode presumes reduction of the entire diversity to certain "laconic" numerical formula, such as Van't Hoff equation in chemistry or Einstein equation in cosmology. The classificatory mode presumes description of the structure of diversity as such and representing it in the form of various classifications not reducible to any "formula". There is an intermediate approach combining these two and describing diversity in the form of parametric classifications, an example is Mendeleev's periodic system of elements in chemistry. It is to be stressed that these basic generalization methods correspond to certain essential properties of the diversity: some of them are most suitable to parametric generalizations while others are so to classificatory ones.

This fundamental dichotomy was stressed by F. Bacon who recognized two main clusters of natural sciences: the "natural philosophy" tends to parameterize quantitative aspects of diversity (physics, chemistry, etc.), while the "natural history" usually classifies its qualitative aspects (biology, geography, geology, etc.). With the Bacon's categorization in mind, a dilemma of scientific monism vs. pluralism arose at the very beginning of emergence of the contemporary science in the 16th century [3]. This dilemma can be outlined briefly as follows.

The scientific monism is an attribute of the classical paradigm, it had been inherited from an Antique idea of the "first principle" ruling the entire Cosmos, which was updated subsequently by the Biblical faith that such a "principle" was actually the Divine Plan. This standpoint presumes unanimity in the natural sciences, according to which there could and should be only one "right" 
vision of any natural phenomenon to which the only "right" concept or theory corresponds, all others being of subsidiary significance (as particular, transitional, etc.) or just wrong. One of the most spectacular expressions of this conviction is a famous (among Soviet people) V. Lenin's mantra "the Marxist doctrine is omnipotent because it is true". In particular, monistic paradigm, especially in its version of the contemporary physicalism, discriminates the above two clusters by considering parametric generalizations the only consistent scientifically. Respectively, it declares all cognitive activity based on classificatory generalizations just a "stamps collecting".

An opposite treatment developed by the non-classical paradigm presumes that any natural phenomenon is too complex to be exhaustively represented by a single finalized concept or theory. Respectively, a pluralistic viewpoint is suggested, according to which any concept captures just a particular manifestation of the phenomenon being studied, so all such partial concepts or theories are of more or less equal status and it is their combination that provides some integrated representation of that phenomenon. This standpoint substantiates multiplicity of the approaches to the studying natural phenomena as a normal state of the natural science in general, therefore the above two clusters of the latter are endowed with an equal scientific status. These approaches are realized as research programs, each developing a particular concept/theory most adequate to certain manifestation of a natural phenomenon, be the latter the entire nature or any of her particular aspects, fragments, levels, etc. [4].

Biology is one of the most "classifying" natural sciences. Indeed, it is probably the only science branch that has developed a special discipline dealing, exactly and first of all, with the structure of diversity as such. In biology, this is diversity of living beings, or biological diversity (aka biodiversity), and this discipline is biological systematics (or systematic biology). Though its subject area is usually defined as the entire biodiversity, it deals actually with but one of its manifestations conventionally termed taxonomic diversity, others being explored by other biological disciplines (biogeography, synecology, sociobiology, anatomy, etc.). Thus, systematics explores taxonomic diversity and describes its structure in the form of various taxonomic classifications. By this, systematics is of fundamental importance for the entire biology: as a matter of fact, it is this discipline that shapes, by and large, the subject areas for many other biological sciences, such as microbiology, mycology, botany, zoology, etc. Due to its fundamental significance, the systematics quite naturally attracts attention of the philosophers exploring foundations of both biology in general and some its key concepts such as evolution, hierarchy, species, etc. [5-10].

In the systematics itself, there is a variety of approaches to the study of the taxonomic diversity. The most important of them are formalized as taxonomic theories and developed into research programs peculiar to this discipline. They differ in their ontological and epistemological foundations, in their principles of defining object, tasks, in the methods of this discipline and in the ways of representing the structure of biodiversity by classifications. These programs change with the development of systematics and biology altogether, depending largely on changes of the general scientific-philosophical contexts. In its turn, the changes of the programs dominating at one or another stage in the history of systematics have a significant impact on understanding how biodiversity is structured and, accordingly, what is the structure of the entire subject area of biology.

As the systematics deals with the same natural phenomenon (the above taxonomic diversity), principal question arises, if it has to follow the only universal research program or rather there can be several of them equally viable. These two positions of rather philosophical kind are known as taxonomic monism and taxonomic pluralism, respectively, they have been actively discussing during the last several decades $[8,11,12]$.

Taxonomic monism presumes that the taxonomic diversity should be uniformly conceptualized and should respectively be described by a single "right" classification, be it either the Natural system of earlier classics, or the general purpose classification of phenetics, or the phylogenetic classification of phylogenetics. The most devoted adherents of each of these approaches, being monists, believe that it is their theory that says a "final word" in the biological systematics and should be accepted as such by the entire taxonomic (and eventually biological) community. And if you replace Marx in the above Lenin's mantra with any other person you idolize (Linnaeus, Hennig, whoever else), it makes no much difference of whose particular "behalf" you turn down or suppress opponents' viewpoints. 
To the contrary, taxonomic pluralism acknowledges that the taxonomic diversity is multifold and that its particular manifestations, if naturally individualized, are of equal biological meaning and scientific (cognitive) status. Respectively, all taxonomic theories and research programs dealing with such particular manifestations are also of equal biological meaning and scientific status. Thus, neither of them may pretend to gain a privileged position in the biological systematics considered in its wide sense. Actually, they all explore and classify their "own" particular manifestations of the entire taxonomic diversity and, by this, structure the latter the ways making various aspects available and suitable to considerations by other biological disciplines. For instance, phylogenetic program structures taxonomic diversity historically, while typological program do that structurally, and biomorphic program uncovers complex morpho-ecological aspect of taxonomic diversity.

The first attempts to recognize explicitly and to discuss the research programs in systematics and to evaluate their scientific status were undertaken in the 1960-70s; recognized appeared to be but three principal "systematic philosophies" most vividly discussed at that time, namely phenetics, cladistics and evolutionary taxonomy [6,13-16]. However, this "three philosophies" viewpoint did not take into consideration or drastically reduced significance of other "philosophies" not so actively discussed then (typology, biosystematics, ecomorphological approach, etc.). Therefore such an oversimplification provided a very distorted representation of theoretical foundations of the of biological systematics, including diversity of research programs actually operating in it, their historical and scientific-philosophical roots, their mutual interactions and influences, their contributions to the development of both systematics itself and the overall biology.

In this article, a brief overview of the principal research programs in the biological systematics is provided guided by their scientific and philosophical foundations regardless of their "popularity" [11]. One of the tasks was to show real diversity of these programs, contrary to a received viewpoint reducing it to a minimal level. This task explains a pretty extensive list of references, though it includes most important issues only. Another task was to show why and how these research programs are substantiated and developed and why it is normal for the biological systematics to be pluralistic in this respect. With this, the main attention was paid to ontological and epistemological prerequisites for elaborating taxonomic theories and developing research programs that implement them. This task also requested references to a number philosophical literature to substantiate the author's position.

Accordingly to the above main tasks, the present overview is suggested to begin with illumination of some principal ideas concerning philosophical foundations of the biological systematics, as they understood by the author, including general principles of elaboration of its own taxonomic theory.

\section{Some basic elements of the systematic philosophy}

Any scientific philosophy, considered in general, deals primarily with justification of the theoretical knowledge in science. Thus, the "systematic philosophy" actually presumes analysis of possible ways of developing theoretical foundations of the biological systematics as a whole.

Obviously, if systematics is considered a scientifically sound discipline, it is to develop its own taxonomic theory (TT). However, despite a significant number of books entitled "principles" or "foundations" of the systematics, no sufficiently well-substantiated TT is known to exist currently. Moreover, hardly any satisfactory understanding seems to exist among taxonomists of what kind of theory it should or could be. There were but few earlier attempts to consider some basic premises and principles of what might be called beginnings of TT, but they were too formal $[7,17,18]$. Apparently, the main reason for such a very deplorable situation is that substantiations of particular classification approaches have been predominated previously, instead of posing the very task of developing the TT in its quite general understanding that would cover the entire biological systematics dealing with multiplicity of both manifestations of biodiversity and the ways of studying it.

Any serious consideration of this important issue would first require an ascertainment of how theories of various levels of generality can be built in different scientific disciplines. However, this 
would lead us away from the main topic of the present paper, especially taken into consideration diversity of viewpoints on this matter. Therefore, without going deeply into this issue, it seems to be enough, for the purposes of this article, to offer the following general declarations concerning just the taxonomic theory $[12,19)$. The latter can be defined as a conceptual system containing generalized theoretical knowledge about what and how biological systematics explores. The answers to the question "what?" make up the ontological part of the theory; they fix the essential characteristics of the object of systematic research. The answers to the question "how?" constitute the epistemological part of the theory, they fix the basic principles of study of this object. Together, these answers constitute a conceptual framework of a TT thus defined.

From this it follows that the main purpose of any TT is faming theoretical context in which systematic research are conducted and concrete classifications are developed. As such, this theory serves as a general basis for the formation and functioning of any research program in biological systematics. Development of such a theory is a most important and an ultimate aim of the above taxonomy as a theoretical part of biological systematics.

\subsection{One Umgebung - many Umwelts}

So, one of the first and the most principal tasks of TT, in its most general sense, is defining an object (or a subject area) of the entire biological systematics. With this, a lot of serious problems arise related not even to the theory itself but rather to the philosophy of systematics - not in the above Hull's but in a more general sense concerning its ontological foundations. They deal with explication of what this biological discipline in general and its various sections in particular do actually investigate.

All natural science, by an initial condition, is aimed ultimately at comprehending and describing nature in her entirety and in all of her manifestations and details - that is, what she actually is as an objective reality. However, nature is so global and diverse in all her manifestations, while the human cognitive possibilities are so limited, that it is fundamentally impossible to embrace her as a whole with a single gaze and to reach a complete knowledge of her expressed by a single exhaustive generalization. Instead of a "global" comprehension of Nature, cognized actually are her "local" manifestations (particular aspects, fragments, etc.).

One of the important formalizations of such a "fragmented" construction of the cognitive situation, in which each natural science is functioning, is a thought-provoking conception developed by a zoopsychologist J. von Uexküll [20-22]. He suggested to distinguish two main levels in the reality, to which cognitive activity is addressed, the whole nature as such (Umgebung) and its actually cognizable manifestation (Umwelt). The fundamental difference between them is that Umgebung exists as the real world in its wholeness around and besides a cognitive subject, while each particular Umwelt is fixed by that subject in the course of the latter's cognitive activity and does not exist out of it. To understand the core idea of the Uexküll's suggestion, its certain analogy to distinguishing fundamental and realized niches in ecology may help: the first refers to the entire set of conditions under which organisms can survive, the second is shaped by selective reaction of organisms to these conditions in a particular place and time [23]. Thus, the Uexküllian stratification seems to describe quite adequately the selective nature of reaction of a cognitive subject to the world being cognized.

From the Uexküllian perspective, any cognitive activity begins with preliminary outlining a particular Umwelt and continues with exploring and describing its properties. Each Umwelt is outlined not arbitrarily or accidently but by means of certain concepts with which an explorer identify something as a concrete object to be cognized in the surrounding world. Thus, if the Umgebung is the objective reality as such in its totality, then an Umwelt is a kind of a "conceptual reality" construed by an explorer as a concrete subject area to which concrete cognitive activity is applied. Background knowledge about this conceptually construed reality is formed on the basis of certain ideas about what is significant or essential for recognition a particular manifestation of the Umgebung. For example, when starting to study certain group of organisms, one can set forth a task of reconstructing diversity of archetypes, or diversity of biomorphs, or hierarchy of monophyletic 
groups, or else. The phylogeny that generates the latter hierarchy can be interpreted classically in its wholeness (according to Haeckel or Simpson) or reduced to cladogenesis (according to Hennig). Or, on the contrary, one can discard all prior considerations of the structure and causes of biodiversity as a natural phenomenon and deal with but separate physically perceived organisms; this is also a specific background knowledge though with very poor metaphysics greatly trimmed by means of the "Occam's razor".

The best way to ensure that the Umwelts being individualized correspond actually to certain biological phenomena seems to be indication of supposed objective causes (initial, proximal, formal, material, etc.) structuring the biota and thus generating various manifestations of diversity of organisms. It is presumed that each such Umwelt, recognized as a basic part of the subject area of the respective biological discipline, is natural to an extent that its causes are natural. The latter makes its exploration biologically meaningful. To the contrary, any Umwelt defined by a formal ontology, i.e. without reference to its natural causes, apparently devoid of biological meaning.

As it is evident from the preceding, any transition from the whole Umgebung to one or another particular Umwelt is based on a reduction operation. As far as systematics is concerned, such a reduction begins with "cutting" something called biodiversity from the entire very complex nature. As soon as the biodiversity is individuated, it becomes clear that it is also very complexly organized by itself, so the taxonomic diversity is singled out from the entire biodiversity, with other of the latter's manifestations (ecological, biogeographic, biosocial, etc.) being discarded. At the next reduction step, the taxonomic diversity undergoes further decomposition by distinguishing its own aspects, e.g. phylogenetic (emphasis on kinship), typological (emphasis on structural plans), biosystematic (emphasis on diversity of populations), etc. Further, for example, within the phylogenetically defined diversity, its cladogenetic and anagenetic aspects can be distinguished and analyzed separately.

Thus, the above transition from overall Umgebung to particular Umwelts can be represented as a kind of "reduction cascade", at different steps of which particular cognitive tasks of different levels of generality are successively formulated and solved. All this is accomplished by a cognizing subject with the help of various epistemic tools: it is this subject that decides what is essential and what is not for distinguishing particular Umwelts. Evidently, such a stepwise reduction leads to unavoidable sequential loss of some part of the objective content of the entire Umgebung (nature as such) at each reduction step. Therefore, this content is least lost at the very beginning of the reduction cascade and most lost at its end; accordingly, in the same direction an accumulated effect of a subjective "input" into particular conceptually construed Umwelts increases.

What is important to stress is that such a reduction is potentially multiple at every step of the cascade. Indeed, any complexly organized natural phenomenon can be represented by several more simple cognitive models (in their general epistemic sense), each fixing its particular "essence" [24]. Such a multiplicity of the Umwelts recognized at each step of reduction of a more general phenomenon, is an ontological prerequisite of plurality of the approaches exploring that phenomenon from various standpoints.

The main intend of the entire reduction operation is to simplify the object being studied by systematics in order to make it more operational and thus more suitable for applying specific analytical methods. The latter serve as a means of elaborating classifications representing particular Umwelts. As it is evident from the immediate above, any classification is best treated as a cognitive model of respective Umwelt; obviously, it is the better, the more fully it reflects the structure of this Umwelt. Based on such understanding, consistency ("trueness" or "naturalness" in the traditional sense) of classification is assessed with respect to just this particular Umwelt. It means, therefore, that any particular classification can serve as a reliable heuristic or a reference system only with respect to the Umwelt it represents more or less adequately.

The latter seems to make questionable a possibility of elaborating something like general reference system (in sense of [25]) that would be more meaningful biologically than, say, a universal alphabet. Such a pessimistic conclusion is grounded on the above ontological premises of "natural" substantiation of particular Umwelts. Indeed, respective manifestations of taxonomic diversity they refer to are presumably resulted from actions of certain not much correlated causal factors-say, 
historical and structural. Their (quasi)independence means that they are complementary and linked by a kind of uncertainty relation: fixing unequivocally any one of those manifestations of the diversity makes problematic fixing as unequivocally its other manifestations [12,19]. Due to this, elaboration of some "integrated" classification as a cognitive model of such multi-Umwelt phenomenon seems to be quite problematic.

\subsection{Taxonomic theory as a quasi-axiomatics}

Every natural science theory includes some elements of axiomatics. This means that it contains more or less clearly formulated statements about the subject being studied (analogues of axioms) and the principles of its research (analogues of inference rules). Considered from a philosophical standpoint, the former constitute ontology, the latter do epistemology. Such a construction of a taxonomic theory (TT) by using at least some elements of the axiomatic method is advantageous in that it allows to formulate more explicitly its basic statements and thus to structure more evidently the theory itself.

The movement toward this aim has begun with the works of the early taxonomists developed the scholastic program in the 16-18th centuries [12]. Subsequently, attempts of this kind were undertaken repeatedly: some were aimed at developing basically universal systems, while others dealt with foundations of particular research programs. Here the author's position is presented very briefly to show why and how theories developed by research programs in the biological systematics can be are substantiated $[12,19]$.

It must be emphasized first of all that the TT is being developed as a quasi-axiomatics. This means that, unlike formal axiomatic systems of mathematics and logic, its basic conceptual constructs are initially introduces as biologically sound. Usually, in various systematic textbooks, all such constructs are called "principles" without distinguishing between their different cognitive functions. However, as it is seen from the immediate above, in the framework of the axiomatic approach it is necessary to divide them into two main categories, namely quasi-axioms and inference rules. The former have an ontological status and outline an Umwelt under study, while the latter have an epistemological status and deal with the principles of investigation of this Umwelt; only these rules deserve being termed "taxonomic principles".

Non-formal status of quasi-axioms means that they refer directly to certain objective (real) manifestations of the Umgebung. It is this reference that allows to suppose that an Umwelt, defined by certain set of quasi-axioms, corresponds to certain natural phenomenon and by this is real ("natural") in a traditional sense. This makes exploration of an Umwelts thus fixed biologically meaningful; what is quite important, the same meaning can be ascribed to a classification as its cognitive model. To the contrary, artificially construed Umwelts by formal axioms with no clear biological references makes as formal (biologically meaningless) respective classifications.

Though an axiomatic method of construing any theory presumes as strict and unambiguous as possible definitions, this requirement can not be followed literally in case of natural science disciplines including biological systemtics. Its implementation is limited by the principle of inverse relationship between the rigor and meaningfulness of concept definition [26]: the more strictly a concept is defined, the less likely there is something in nature to which it may correspond [1]. Therefore, any definition of an Unmwelt, claiming to be biologically meaningful, is deemed to be imprecise semantically and should be formulated taking into consideration some conditions of the fuzzy logic (see [27] on it). The latter means, among others, that such "fuzzy" definitions seem to entail an unfeasibility of their strict and unequivocal applications in studying the structure of biodiversity. The biological concepts most pertinent to this issue, that come to mind, are those of taxonomic rank $[8,12,28]$, homology [29-32], and of course species [8,9,10,33-37]: impossibility of their strict and unambiguous definitions leads to the "fuzziness" of these concepts reflected by a plurality of their particular meanings.

It is to be stressed especially that quasi-axioms and inference rules (principles) within a TT do not work separately, but conjointly in a single package. This means that the basic (for this TT) statements relating to ontology and epistemology should be meaningfully compatible with each 
other. For example, if an Umwelt is defined phylogenetically, then the principles should specify how a classification should be developed to reflect just the phylogenetic pattern and not anything else. In general, this compatibility is formilized by the principle of onto-epistemic correspondence [12,19].

It follows from the above stepwise reduction cascade (see section 2.1) that the sequential reduction of the overall Umgebung to certain set of Umwelts results in generation of respective particular quasi-axiomatics of different levels of generality. On this basis, a hierarchy of TTs allocated to these levels can be consequently construed. Thus, taxonomic theory considered in its most general sense is a rather complex multilayer construct. It consists of several levels of theoretical generalizations, each solving specific tasks allocated to a respective level. Theoretical provisions of the highest level of generality constitute the general taxonomic theory (gTT), while those belonging to the lower levels are particular taxonomic theories (pTTs).

In this hierarchical "conceptual pyramid", the gTT plays the role of a framework concept in relation to various pTTs and can be considered as a taxonomic metatheory (i.e., "theory of theories") for them. Within such a "pyramid", particular pTTs arise as different detalizations of the statements of the gTT. The main task of the latter is to outline correctly (including biologically sound) cognitive situation for the entire biological systematics, including its basic ontological and epistemological components. Thus, gTT can be imagined as a set of interconnected general judgments about the general properties of the taxonomic diversity (ontology) and the general principles of its study (epistemology). This theory is intended not to elaborate concrete classifications, but rather to formulate (as prescriptions and restrictions) the grounds for possible ways of formulating and solving exploratory tasks systematics deals with. So, it is the gTT that can more than justifiably be claimed a "systematic philosophy".

There are two principal modes of construing the gTT. One of them refer primarily to ontological quasi-axioms, another accentuates on epistemological reference rules. Thus, taxonomic pluralism is observed even at the most general level of theoretical basis of the biological systematics.

The ontology-based gTT specifies first how particular Umwelt is to be outlined: for instance, if causes of diversity of organisms should be indicated or not, and if indicated, which particular ones-historical in phylogenetics, or structural in typology, or functional in biomorphic, or else. If evolutionary process is referred to as the main cause of taxonomic diversity, it can be interpreted as an adaptatiogenesis or as a more "formal" cladogenesis. On this basis, it is then specified (quasi-axiomatized) which particular relations between organisms are taken into account-only kinship or only similarity or some combinations thereof. Based on these basic assumptions, certain taxonomic principles are developed: some of them entail homologization, character weighting, similarity assessment, etc., while others deal with inferring particular phylogenetic schemes, and the next with elaborating phylogenetic classifications based on these schemes. The same general design is true for any other biologically meaningful quasi-axiomatics, be it typological, biomorphic or else.

On the other hand, the epistemology-based gTT considers basically not the diversity itself, but the methods of its study. For example, it is permissible to postulate that systematic research should be subordinated to certain universal fairly formalized reference rules. Particular implementations of such a requirement are pTTs in which, for example, logical or computational procedures are set as of primary importance. Unlike the biologically meaningful quasi-axiomatics just considered, these ones do not presume any references to particular Umwelts, which make respective pTTs independent of the ontologies and, by an initial provision, universal in their applications.

As it is seen, the outlined quasi-axiomatic method of developing theoretical foundations of the biological systematics makes it rather easy to understand the whole structure of both the gTT (which is still an imaginary rather then well-established construct) and the variety of pTTs detailing the latter.

\section{An overview of the research programs in systematics}

Research programs in the biological systematics appear and function as a means of implementation of particular taxonomic theories. The latter develop not by their own, but in certain philosophical-scientific contexts, one way or another responding to the challenges that systematics 
faces at one or another stage of conceptual development of the natural science in general. Changes of the programs take form of scientific revolutions shaping historical development of this biological discipline [12,38]. So it is reasonable to begin our overview of the research programs in systematics with a very short outlining of its conceptual history.

The first was the scholastic program acting from the 16th to the 18th century (from Cesalpino to Linnaeus): its principal task was elaboration of the Natural System of all plants and animals based on strict application of the universal logical genus-species scheme of division by essences serving as a unified basis of this division (fundamentum divisionis unis). Thanks to this systematics emerged as a fully-fledged classifying natural science according to one of the then prevailing concepts of rationality. One of its most influential ideas was that an essence of organism is exhausted by its own properties and does not includes organism's relations with its environment.

The next revolution took place at the fall of the 18th and the beginning of the 19th centuries, its main driving force was a kind of "biologization" of the systematics presuming a more meaningful understanding of both the Natural System and the natural method leading to it. It spawned several research programs, each with its own natural-philosophical justification. Of these, the program of natural systematics (Adanson, Jussieu, Candolle) appeared initially to be very powerful as it met requirements of empirical science paradigm. As a matter of fact, it was Adanson to declare first that the Natural System should be based on the analysis of all available features peculiar to particular groups instead of enigmatic unified "essences"; this taxonomic concept turned out to be incorporated into the phylogenetics by the end of 19th century. The typological program (Cuvier, Baer, Goethe) based on the type concept (in its various interpretations) appeared to be not only of equal importance but also more viable as it lasted in the 20th century. Others were either premature (the first version of evolutionary systematics of Lamarck) or non-viable (Oken's organismism, MacLeay's quinarism).

At the end of the 19th century, the next revolution in systematics was associated with the active development of the natural philosophy of transformism and spawned two research programs, namely "classificatory Darwinism" (by Darwin) and "systematic phylogeny" (by Haeckel), both played a key role in the development of systematics in the 20th century. The first half of the latter was marked by a revolution that responded to a challenge of the positivist philosophy: it prompted systematics to develop phenetic and numeric programs, as well as biosystematics as a kind of a "hybrid" of the positivist ideas and the classificatory Darwinism. In the second half of the 20th century, not without an influence of the ideas of post-positivism and modern conceptualism, an interest to phylogenetics revived in the version of cladistics, revolutionary in its own way. On the other hand, the biomorphic program became active enough, reviving partly an idea of understanding the Natural System that had been developed by A. von Humboldt at the beginning of the 19th century. Finally, for the time being, it seems that another scientific revolution in systematics is brewing: it is associated with the emergence of the evo-devo program, which is actually a modern version of the "biologization" of systematics based on the synthesis of evolutionary and developmental biology as opposed to reductional cladistics.

The subsequent subsections provide a review of the research programs in biological systematics that have been developing over the 20th and at the beginning of the 21st centuries. Some of them basically continued the above ideas formed in the 19th century (typological, phylogenetic, etc.), others emerged de novo in this period (phenetic, numercial, evo-devo, etc.). An order of presentation of these programs corresponds basically to some "scale" of an amount of their biological content: their list is opened by most reductional and formal programs (phenetic, rational, numerical) and finalized by most biologically sound (typological, biomorphic, phylogenetic, evo-devo).

\subsection{The phenetic program}

This program develops and formalizes an old idea of empiric knowledge and, as such, goes back to the folk systematics (see $[12,39,40]$ on the latter). The beginning of its persistent formation in the scientific systematics was laid by the works of the "anti-scholastics" of the second half of the 18th 
century. Usually, M. Adanson's approach is mentioned in this connection-to an extent that the founders of modern numerical phenetics used to call it "neo-Adansonian" [41,42]; however, such identification was shown to be incorrect $[6,43)$, the Adansonian methodology actually forerun one of numerical cladistic approaches [44]. The genuine phenetic concept was expressed at that time by German naturalist J. Blumenbach: he stated in his "Handbuch der Naturgeschichte" that the "animals that are similar in 19 structures and differ only in twentieth should be grouped together" (see [12] for reference).

In the 20th century, the phenetic program in its rather strict sense is substantiated by a classification theory based on the positivist philosophy of science, as its early ideologists stated explicitly $[25,41]$. It is closely related to the numerical program (see section 3.3 ), so they are often almost identified. However, this is not correct: the phenetic theory deals with what is studied (ontology), while the numeric one deals with how that "what" is studied (epistemology).

According to this philosophy, in cognitive situation of the phenetic systematics the background knowledge is minimized in order to exclude its "metaphysical" (declared "unscientific") content. Respectively, phenetically defined Umwelt is simply a set of observable physical bodies with their characters, i.e. organisms. At the same time, the subjective influence is also excluded as much as possible: all operations on those "physical bodies" - their description, comparison, etc. - should be depersonalized and reduced to some elementary automated actions. Phenetic classification is developed as purely empirical (in a philosophical sense): it should be nothing more than a generalization of the observed facts, which makes it independent of any biological theories.

In developing phenetic classifications, the only basis for grouping organisms is their mutual similarity as such, which is supposed to be theoretically neutral. However, the latter is not true [45-48] so the phenetic program seems to lack its initial "as-if empiric" philosophical background. This similarity is evaluated across the totality of unit (elementary) characters used in the comparisons without any preliminary assessment of their significance ("weight"). One of the most serious restriction on the choice of characters is that they should describe organisms themselves (morphology, physiology, genetics, etc.) but not their relations to their environments (ecology, etc.) [41,42]. Such a "weighting" ascends evidently to the essentialism of earlier (scholastic) taxonomic theory [12]. The resulting taxa in phenetic classifications are designated as phenons; ontological interpretation of both them and their ranks is nominalistic.

The main purpose of the phenetic classification is quite pragmatic: it should not reflect some mysterious "naturalness", but be "useful". The usefulness of a classification depends on its informativeness, i.e. on the volume of information about the diversity of organisms contained in it. The maximization of the information content in classification is achieved by increasing the number of characters used for its elaboration: roughly speaking, the more characters, the better. This condition is substantiated by an ad hoc hypothesis of character nonspecificity coupled with mathematical principle of convergence: it is assumed that classifications, if "starting" from different initial sets of characters, should converge asymptotically with the maximum possible increase of number of characters [41,42].

The purely "technical" nature of the phenetic classifications means that they are not evaluated from the point of view of their naturalness in its traditional meaning; it is replaced by certain operational criteria of assessment of classification informativeness ("Gilmour-naturalness"). The most informative classifications that can be used to solve many different tasks are termed "general purpose" ones. With reference to the above principle of convergence, potential attainability of a single stable reference system as an ideal of the phenetic systematics is supposed. Along with it, various "special purpose" classifications can and should be elaborated to solve certain particular research and applied tasks; there can be a lot of them, they can be very different in their information content, but all of them are subordinate with respect to the general purpose classification. So, the phenetic program is monistic with respect to the general purpose classification and pluralistic with respect to the special purpose ones.

The phenetic program, supplied with the numerical methods, was most popular in 1960s; at present, it became supplanted by the phylogenetic program in its cladistic and molecular versions (see section 3.7 on them). In this regard, it is important to keep in mind that the latter borrowed some 
important points of the phenetic theory. Thus, in the phylogenomics, an idea of reduction of organism to a set of automatically identified unit characters appeared to be perfected: these are nucleotide base pairs in DNA and RNA sequences. In cladistics, obvious elements of the phenetic theory are introduced by the positivist principle of total evidence [49-51]; in traditional terms this means nothing but realization of the above phenetic idea "the more characters, the better."

From the point of view of the philosophy of science that focuses on modern conceptualism, the main problem of the positivism-based phenetic program is that a strictly empirical knowledge, devoid of any theoretical basis referring to certain natural ontology, is impossible in the natural science [46,52]. This key standpoint means that both the phenetic theory itself and the program implementing it droped out of the framework of the contemporary science with its dominating post-positivist philosophy.

\subsection{The rational program}

Rationality, understood in its general sense, forms the very basis of the science distinguishing it from other forms of the cognitive activity. Among various versions of the scientific rationality $[53,54]$, a deductive one is most relevant to substantiation of the rational program in systematics taken shape during the 20th century, as it is understood by the author [12,55]. It is based on acknowledge of paramount importance of such syllogistics, in which particular judgments are deduced from general ones; with this, it is presumed that the truth of the former entails by the truth of the latter. The general aim of such an approach in biological systematics is to develop a kind of rational classifications, "all elements of which are derived on the basis of some general principles, certain theory" [56] (p. 164). It is clear that formulation of taxonomic theory as a kind of quasi-axiomatics (see section 2.2) fits completely the conditions of such rationality.

Initial judgments, with which formation of the rational program in systematics began, are twofold. Some of them are related to the object being researched, i.e. to ontology; this can be termed an ontic rationality. Others relate to the principles of research, i.e. to epistemology: accordingly, they constitute an epistemic rationality. Thus, this rational program is divided into two subprograms; they are similar in the deductive substantiation of particular judgments but differ in the latter's content $[12,55]$.

One of the first versions of the onto-rational program in systematics was proposed by a botanist A.-P. de Candolle (actually, he was the first to coin the term "rational classification") at the beginning of the 19th century, who based his theory on the principles of symmetry borrowed from crystallography $[57,58]$. In a more general form, the idea of rational systematics was formulated a hundred years later by a natural philosopher H. Driesch [59]: he called for uncovering some general law of orderliness of diversity of biological forms that would be analogous to the natural laws of orderliness of chemical elements in physical chemistry or geometric figures in geometry. A rational classification based on such law becomes a powerful heuristic that allows certain predictions about still unknown forms. Thus, it is reasonable to call the onto-rational systematics nomothetic [60]: it reveals the general laws of taxonomic diversity instead of presenting the latter as but a list of taxa with their diagnostic characters. It is evident that the taxa recognized within the onto-rational taxonomic theory are interpreted realistically as natural kinds in the sense of W. Quine [61].

Implementation of one of the Driesh's ideas led to an aspiration to elaborate parametric classifications of living forms analogous to the above periodic system of elements in chemistry [62-63]. The latter means that such classifications should not be construed on a strictly hierarchical ("vertical") basis, "horizontal" relations between biological forms being most important instead. The main problem here is that the biological forms are much more complex than the chemical elements; therefore, it is difficult to recognize a key parameter by which their periodic system could by arranged. Such a parameter is usually suggested to define as complexity of organisms, but it does not lend itself to a satisfactory enough universal definition allowing for developing a single scale of complexity [64-65]. So the principal idea of this version of onto-rational program in systematics seems to be hardly resolvable in general, though some of its applications are of certain interest as they uncover some important properties in the ordered structure of biodiversity. 
There is another version called rational by its creators [66-68], which fits conditions of the onto-rationality. In this case, rationality presumes deducing classifications from orderliness of the diversity of ontogenetic patterns. Here this version is considered as a part of the epigenetic typological subprogram (see section 3.4).

The episto-rational subprogram focuses on certain general inference rules governing the particular exploratory procedures in the systematics. Such a standpoint presumes that it is these rules that are primary and all taxonomic principles and methods are to be inferred from them, while ontological considerations being discarded. In the classical systematics, this general conception had led to a fundamental monistic idea of the "natural method", proper application of which, by an initial intention, had per se to provide the natural classification. According to M. Adanson [69], this method "should be universal or overall, i.e. there should be no exception for it" (p. civ). This general idea was first implemented by the above mentioned scholastic systematics of the 16th-18th centuries in a form of the universal genus-species scheme [12]. The post-scholastic systematics rejected this particular scheme, but the very idea was retained and led eventually to development of two particular research subprograms. In one of these, the logical argumentation is taken as the basis, while another accentuates on mathematically based judgments.

An idea of strict subordination of taxonomic principles of the biological systematics to some "general logic" was expressed not a once in recent times [17,18,57,70]; as a matter of fact, it explicates a rather old idea that any classification is but a logical procedure. Some fragmentary attempts to implement it were based on application of the requirements of the formal axiomatic systems (see section 2.2); a more recent and quite developed general solution is offered by so-called classiology [71]. They all presume that any classification theory derived from some "general logic" is applicable to any phenomena (natural, social etc.) studied by any classifying sciences regardless of their natural ontology. However, no one pure "logical" taxonomic theory for the biological systematics has been proposed so far (if not to count those dealing with identification keys), and no biological classifications of such kind are known to be elaborated. Thus, the main idea of a would-be "logical" research program in systematics still remains but a kind of "declaration of intent".

In considering a productivity of such a theory for the biological systematics, of prime importance is fundamental issue of any relevance of its basic idea to it. The systematics asks by and large about objective (real) biodiversity and tries to answer this question in a sound manner. However, every logical system is just a specific tool designed to ensure the logical consistency of derivative particular statements with respect to the more general ones, all within a particular formal axiomatic system. Within the latter, such a tool asserts the "logical truth" of the conclusions obtained with its help, but it does not say anything about their "natural truth" with respect to the reality being studied-just because it does not consider this respect at all [72]. So, the program in question does not seem to expect neither the very question nor an answer as to how "logical" classifications may relate to the reality and, if they relate, how to ascertain this.

If the above declaration is decided to follow literally, it is to be taken in consideration that any appeal to some "general logic" looks quite naïve, as there exist a lot of formal logical systems [73], some of which (binary, probabilistic, fuzzy, modal, etc.) are relevant to the systematics. Thus, the next key question arises, now it is about basis for a choice of particular logical systems for deducing particular taxonomic theories applicable for elaborating biologically meaningful classifications.

As far as such question is concerned, one of possible answers to it is provided by the above principle of onto-epistemic correspondence (see section 2.2). According to the modern conceptualist standpoint underlying this principle, it is the ontology that drives epistemology (including logical inference rules) and not vice versa. Or, in other words, the principles of elaboration of biologically meaningful classifications are to be inferred from background assumptions about properties of the taxonomic diversity rather than from any "pure logic" [12,19,74]. So, it becomes clear from this standpoint that any kind of a pure "logical" research program in the biological systematics seems to be not feasible.

A part of the episto-rational subprogram is the numerical one based on primarily mathematical foundations of taxonomic principles and methods. Because of its significant influence on 
development of the biological systematcis, it probably deserves a status of a research program of its own; it is considered in the following section.

\subsection{The numerical program}

As it was just noted, this is actually one of the versions of a more wide episto-rational subprogram, though deserving a status of a distinct program. Its source lies the natural-philosophical idea that the "Book of Nature is written in the language of mathematics" announced by G. Galilei in the 17th century [75]. Based on it, I. Kant at the end of the 18th century expressed one of the key ideas of the modern physicalism: "in any special doctrine of nature, there can be only as much proper science as there is mathematics therein".

In the post-scholastic systematics of the 19th century, H. Strickland should probably be considered one of the forerunners of the numerical program: based on the then rather popular so called "taxonomic map" metaphor [76], he likened the similarity between groups of organisms to the distance between territories on a geographical map: the longer is distance, the less is similarity [77]. At the beginning of the 20th century, E. Smirnov put the key idea of this program this way: you need to "establish those rules and laws that determine the relative position of the phenomena studied. The expression of these laws in the form of mathematical formulas is the highest goal that systematization strives for " [78] (p. 359). Smirnov called such a taxonomy "exact"; somewhat later its supporters called it "numerical" and then, quite straightforwardly, "mathematical". The general design of the numerical program in taxonomy was framed mostly in the 1960-70s [41,42,79,88]. Based on the above Kant's aphorism, adherents of this program consider it the only one deserving the title of scientific in the physicalist sense of the latter and deem it as the most significant scientific revolution in the contemporary systematcis.

The main content of this program can be formulated in two general principles. Firstly, relations (similarity, kinship, etc.) between organisms and sets thereof can and should be measured quantitatively. Secondly, the structure of relations thus quantified can and should be transformed into a classification by means of quantitative methods. Implementation of this program is provided by a lot of methods developed to solve various particular classificatory tasks within the general numerical idea.

It is clear that the numerical program, based mainly on epistemology, does not have any subject domain of its own. It concerns the issues relating to ontology just as far as an object to be studied is to be "adapted" to the needs of quantitative methods by means of its total reduction. So, any function of this program is limited to serve as an analytical supplement to the research programs based on ontological considerations, of course those that consider such a reduction acceptable.

Depending on which particular biologically meaningful tasks are solved using quantitative methods, the program under consideration is divided into two main areas, viz. numerical phenetics and numerical phyletics.

Numerical phenetics $[41,42,81,82]$ provides quantitative methods for implementation of the phenetic and partly the biosystematic programs (see sections 3.1, 3.6 on them). In this case, a classification procedure is based on quantitative assessments of the similarities as such, and character weighting is minimized because of lacking any background knowledge underlying it. The main task is to produce such pattern of similarity relations among phenons, in which the differences within each of them are minimized and the differences between them are maximized, with this pattern being transformed subsequently into a phenetic classification.

Numerical phyletics $[81,83-85]$ develops quantitative methods for implementation of the phylogenetic program (see section 3.7 on it); its methods are designed to facilitate reconstruction of phylogenetic relationships. Accordingly, similarity is considered as an indicator of kinship, and character are weighed to select the most reliable indirect evidence of kinship. With this, construction of phylogenetic trees is narrowed down to a formal graph theory without any biological considerations [86]. An ultimate goal of the numerical phyletics is to develop a tree-like structure that can be interpreted as a network of kinship relationships among supposedly monophyletic groups and thus capable to be transformed into a phylogenetic classification. 
Theoreticians of the numerical program, based on their scientific and philosophical preferences, see its undoubted advantages in objectivity, formalization, repeatability, and exactness of the classificatory techniques. However, the latter hold initially one fundamental limitation provided by axiomatic justification of any pure mathematical method. The point is that any formal axiomatics contains certain element of subjectivity [88,89], so an "objectivity" attributed to both the methods developed on its basis and the results of their application, considered philosophically, is nothing more than a myth, although very widespread. Actually, it is eligible to discuss if a method is true or false with respect only to the axiomatics underlying it but not with respect to a particular Umwelt analyzed with it. So it is hardly possible at all to say if a classification obtained by a pure formal method is true or false as a cognitive model of this Umwelt, which makes no sense in any consideration if such a classification is "objective" or not [5]. The only point that can be discussed rightfully is intersubjectivity $[90,91]$, which means only that different researchers, solving the same standard problem using the same standard method, get the same standard result (notorious repeatability). As for exactness of the axiomatically substantiated methods and the results of their application, it is determined only within the framework of the formalizations embedded in the initial axiomatics, and are not necessarily so in others [88,89].

Opponents of this program consider its main idea-primacy of the formal method over biological content-flawed: it reduces biologically meaningful tasks to purely technical ones and thus, from a metaphysical perspective, "puts the cart in front of the horse". As a result, the problem of instrumentalism arises, which means "closure" of the cognitive activity of biologists on the method as such [12,87]. Besides, extreme formalizations implied by this idea are considered its drawback from a biologically meaningful standpoint.

One of the important methodological problems of the numerical program results from a variety of quantitative methods not reducible to any one most general or most "right" [42]. In such a pluralistic situation, the same question inevitably arises, as in the case of the "logical" taxonomic program (see previous section), now it is about selection of a particular method among several available; two general solutions are possible here. On the one hand, the above principle of onto-epistemic correspondence can serve as a basis for such selection: a method is preferable if it is more adequate to the biological content of the task being solved. On the other hand, the choice of a method should be justified "technologically": the better is it formulated within a well-founded axiomatics, the more preferable is it. The first approach is attractive from the point of view of biology, but it contradicts the ideology of the numerical program. The second approach advocated by proponents of the "mathematical taxonomy" [80], as noted above, subordinates the solution of biologically sound tasks to the dictatorship of the formal method and thus brings forth the problem of instrumentalism.

If philosophical questions are left aside, then undoubted practical advantages of numerical program come to the fore. One of these is that numerical methods make possible comparative analyses of large data arrays; this is especially true for the numerical phyletics operating with many thousands of unit characters (nucleotid base pairs). A possibility of quantitative comparisons of different classifications by their characteristics, as well as elaboration of the consensus classifications for those derived from incompatible datasets, are also among practical advantages of the this program. At last, computer experimentations with virtual models make it possible to simulate macroscopic phenomena that are fundamentally unobservable and not amenable to direct experiments, viz. the structure of biodiversity, global phylogeny, etc.

\subsection{The typological program}

The typological way of perceiving and representing "qualitative" structure of the worlds of things and ideas is among most basic aspects of cognitive activity. It begins with personal perceiving and thinking of nature with "gestalts", i.e. integrated images expressing essential features of her various manifestations (aspects, fragments, etc.). The results of such an intuitive perception are then transferred to nature herself: from this, an Antique coception of archetype or eidos as an initial ideal 
form ("matrix") giving rise to a diversity of all real forms had emerged. It also occurred in the general idea of the prototype underlying the natural-philosophical concept of the Scala Naturae, which had a significant impact on the formation of worldview among many naturalists of the 18th and 19th centuries, including active creators of earlier post-scholastic vision of the living matter, such as Buffon and Lamarck [92].

Typological views are usually derived by authorities from the essentialist ones, but this is hardly true. Aristotle's understanding of essence (ousia), which forms the basis of the essentialism in its widespread understanding (ascending basically to Popper), is functional [93-94]; it is this capacity that inspired many taxonomists from scholastics (such as Cesalpino and Tournefort) to early post-scholastics (such as Jussieu and Strickland). In fact, the typology proper, as it appeared in the works of French and German anatomists at the end of the 18th and beginning of the 19th centuries, was based on an idea of proto- or archetype understood structurally as determined by spatial interrelations of body parts of organisms [95-96]. Therefore, the typological program was undoubtedly an original product of the early post-scholastic development of the systematics, with one of its predecessors having had been most probably an Aristotelian I. Jung with his conception of geometric construction of plants (see [12] for details). In the first half of the 19th century, this program was dominating, especially in the systematic zoology.

The central element of the typology in general and of the typological theory in systematics in particular is the type concept. The latter is very multifold and combines many different meanings reflected in a rather rich terminology, so such kind of "typological pluralism" is to be taken into consideration when typology is discussed in general. Therefore, before exposing this program, it is desirable to consider briefly main hypostases of this concept.

In its broadest natural-philosophical sense, a type is likened to a natural Law of Nature: according to A. Naef, "organisms relate to the type in the same way that events relate to the law they manifest" [97] (p.7). From this point of view, both a physical or chemical law and a type thus understood are equally fundamental attributes of nature - though not directly observable and rather conceivable, but nevertheless completely "material" as the metaphysical natural phenomena.

In a more concrete and yet quite natural-philosophical understanding, a type is thought of as a kind of generalized structural characteristic of an organism considered also in a generalized (idealized) form. Such type, expressing a general body plan (Cuvier) or a developmental plan (von Baer) or a metamorphosis of parts of organismal archetype (Goethe), is related to partonomy = meronomy (in sense of $[60,98,99])$. Thus understood, such a "natural-philosophical (arche)type" plays a key role in the initial development of the concept of structural homology (R. Owen), without which no systematic (and indeed any comparative) research is possible [27].

More empirically understood, type corresponds to a combination of properties that are characteristic (typical) for certain group of organisms (or eventually any other objects). Such a group can be distinguished by a researcher on the basis of various reasons: it can be either a taxon in its proper typological understanding, or a monophyletic group, or a life form, or even just a phenon, or else. Thus, such an "empirical type" is largely viewpoint-dependent: it is the researcher who decides, guided by a particular research task, which kind of groups are to be recognized and which properties are to be considered as constituting their types [99]. A kind of quintessence of such an understanding is the concept of "ideal type" by M. Weber playing mainly an epistemic role in the comparative investigations $[1,100]$.

It is the natural-philosophical concept of the (arche)type that is central to the typological research program in the biological systematics. This program realizes a typological theory, according to which the Systema Naturae is a hierarchically ordered diversity of the (arche)types of various levels of generality, from most fundamental to most particular. This conception underlies a general idea of natural classification as the one most fully representing presumed hierarchical structure of the (arche)types diversity. Respectively, taxa are recognized following the general principle of unity of type: each taxon is defined by an (arche)type of certain level of generality most fully expressed in the organisms belonging to that taxon. For this, the characters used to recognize taxa are weighed and ranked in a special way: the most significant are those that allow to characterize most completely the (arche)types and their subordinations. 
It is clear from the preceding that, in elaborating particular typological classifications, the partonomic (meronomic) analysis is primary with respect to the proper taxonomic one $[12,61,99]$. This means that hierarchy of (arche)types is revealed first, then weighting/ranking of the characters attributed to them is carried out, and finally typological taxa are diagnosed by these characters. In order to proceed properly from the hierarchy of (arche)types through the analysis of the characters to the hierarchy of taxa, the principle of ranks coordination is introduced. According to it, characters attributed to the (arche)types of certain levels of generality are used to define taxa of the same levels; this principle ascends to the methodologies of Jussieu and Cuvier. Like taxa of the onto-rational taxonomy (see section 3.2), typological taxa are thought of quite realistically as the natural kinds; accordingly, a real (objective) status is also presumed for their taxonomic ranks $[99,101]$.

The typological program most fully implements general ideas of the natural-philosophy based typological theory(ies) at the macrosystematic level, where differences in (arche)types are most evident. At the generic and especially species levels, its capabilities are significantly lower, since the differences between organisms at these levels do not usually affect the body plans.

The natural-philosoiphical typology has been developing from the very beginning in three main versions, viz. stationary, epigenetic, and dynamic; they were added subsequently with several other versions adapting the original ones to the evolutionary idea [12]. All they might be treated as particular taxonomic theories of the typological kind.

In the stationary typology going back to the ideas of F. Vicq d'Azyr, G. Cuvier, É. Geoffroy de Saint-Hilaire, an adult organism is characterized through a structural general plan (bauplan), determined basically by the spatial (geometric) relations of its components. The overall organismal diversity is structured by detailing these plans from most to least general. Accordingly, the typological unity of taxa appears as a unity of the structural plans of the organisms belonging to them.

In the epigenetic typology (= epitypology) originated from ideas of $\mathrm{K}$. von Baer, the general plan is considered as becoming through the ontogenesis: the epigenetic type is mainly a type of individual development of a particular structural plan. In modern terms, such developmental type can be interpreted as an ontogenetic pattern. The general structure of the diversity of these patterns can be represented by a branching tree, which was suggested to call "Baerian" [102]. The general idea of the modern ontogenetic systematics is most close to this version of typology; in it, the diversity of taxa is analyzed from the standpoint of the diversity of ontogenetic patterns of respective organisms and the taxa are diagnosed by specificity of the patterns characteristic to their organisms[102-106].

The dynamic typology goes back to the ideas of W. von Goethe; it considers the general organismic construction also in a development, but the latter is understood as an "ideal" (imaginary) metamorphosis (transformation) of different parts of an imaginary archetype of some superorganism; this version is called sometimes transformational typology [107]. In accordance to its principal idea, taxon is characterized by a common pattern of transformations of the basic archetype. This typological theory served in the mid-19th century as a basis of the typological concept of homology (Owen); in the 20th century, it enjoyed popularity among some constructional morphologists $[97,108-110]$.

From the second half of the 19th century and especially in the 20th century, the typological program appeared to be in a "shadow" of the phylogenetic program and was almost completely rejected by the phenetic one. Two main arguments were put forward against it: a) the type is an ideal construction, to which nothing corresponds in nature, and b) the type is unchanged, which contradicts the central evolutionary idea of the recent biology. To some an extent, such a negative attitude was aggravated by the fact that the biochemical and especially molecular genetic attributes most popular in the contemporary systematic studies seem to be not amenable trivially to the classical typological interpretation [111].

However, traditionally negative attitude towards typology $(5,9,12,112]$ began to be replaced gradually by a more positive one in the second half of the 20th century. Some of its key ideas were supported by the so called "new essentialism" [113-114], which is acknowledged to be compatible with the evolutionary ideas [115-117], up to a proposal of the "phylogenetic typology" conception [118]. Very interesting in this respect are evolutionary interpreted typological concepts of the 
dynamic archetype (= phylocreod) [119-121] and the phylotype [122-124]: they refer to the stable trajectories of evolutionary development of both particular morphological structures and integrated ontogenetic patterns. The most significant in its promising perspective seems to be a merging of the classical epitypological and the phylogenetic ideas about formation of structural plans of organisms with the most recent ideas on genetic regulation of ontogeneses within the framework of the evo-devo program in systematics (see section 3.8).

\subsection{The biomorphic program}

In the basic structure of biodiversity two principal components are usually recognized, namely ecological and phylogenetic ones: the former corresponds to the hierarchy of ecosystems, while the latter to the hierarchy of monophyletic groups [125]. But, according to a more widened concept, there are three of such components: to those just indicated, biomorphic component should be added, which is a hierarchy of biomorphs, or life forms [126]. The first component is studied by ecology and is outside the scope of the systematics; the second one is explored by phylogenetics, which shapes a specific Umwelt for the phylogenetic program in systematics (see section 3.7). The third component is explored by ecomorphology (in its taxonomic meaning, see below), or biomorphics; it is usually taken out of limits of the systematics proper but recently was suggested to include it in the scope of the latter $[12,127]$

The need to develop verily natural classifications of the "basic life forms", rather than artificial diagnostic keys of the scholastic systematics (like that of Linnaeus), was declared by A. von Humboldt at the beginning of the 19th century. This might become one of the important ideas in the early post-scholastic systematcis, but Humboldt's idea left no evident traces in the then popular taxonomic theories [12]. Sufficiently developed classifications of the life forms in botany and zoology began to appear in the late 19th and early 20th centuries [128-129]. Their main purpose was to reflect diversity of complexes of the morphophysiological adaptations of the living beings as elements of the real ecosystems. By the end of the 20th century, a movement in this direction led to emergence of a fairly developed theory, which was proposed to designate ecomorphology [130-131].

However, the latter term has two meanings. One of them is connected with the study of the meronomic aspect of the diversity of organisms: W. Bock [132] defined its main task as an analysis of morphological adaptations as such. Another is taxonomic meaning: it is associated with the classification of organisms according to their eco- (or bio-) morphological similarities (references above). Taking this ambiguity into account, an introduction of the above term biomorphics to designate just the taxonomic aspect of ecomorphology and to consider it as one of the research programs within the biological systematics seems quite justified.

The main task of the biomorphic program is to recognize biomorphs of different levels of generality and to develop biomorphic classifications on this basis. Biomorphs are distinguished by the biomorphological (eco-morpho-physiological) specificity of respective organisms. Thus, biomorphically defined taxa unite organisms similar in both their ecosystem functions and morpho-physiological features ensuring fulfillment of these functions. So, definition of biomorph does include indication neither of kinship nor of the time and place of origin of organisms, nor of their phenetic similarity as such.

Such interpretation of biomorphs provides the research program under consideration with a particular specificity that is not observed in other branches of biological systematics. As a matter of fact, different organisms of the same species and even different stages of development of the same organism can belong to different biomorphs if they differ significantly in their biomorphological characteristics. For instance, biomorphologically different can be plants depending on their growth conditions, or insect larvae and imagos playing significantly different roles in the ecosystems. So, not the total organisms but rather such elementary units ("bricks") of biomorphic diversity are united in the taxa in respective biomorphic classifications [133].

The elaboration of biomorphic classifications begins with characters weighting and ranking: the most significant are those describing most important adaptive features of organisms as elements of the ecosystems, their rank being determined by the level of generality of corresponding adaptations. 
In the analysis of characters, any distinction between homologies and analogies does not matter, the general "adaptive syndrome" of the organismal features is considered instead. Based on the characters thus weighted and ranked, the entire classification of biomorphs is built up, the hierarchy of which is determined by the hierarchy of respective syndromes. So, classification algorithm of the biomorphics is generally deductive: a common basis for dividing the world of living organisms (for example, a type of metabolism) is initially identified, and then the entire classification is construed from top to bottom following hierarchy of the syndroms detailing successively the chosen basis.

Thus, the biomorphic program is very similar, by its general classificatory algorithm, to the typological program (see section 3.4 on the latter). Their fundamental likeness is in considering a timeless aspect of diversity of organisms and classifying them based on prior characters weighting and ranking. A significant difference is that typological classifications are based mainly on homologies, while biomorphics takes into consideration the entire "adaptive syndrome" of features. At the same time, special emphasis on the functional significance of characters places biomorphics close to the Aristotelian essentialism (ousiology), in which particular attention is paid just to the functional destiny of the parts of organisms (see section 3.4).

Within this research programs, ontological interpretation of biomorphs seems to be quite realistic. This is substantiated by reference to the processes in the natural ecosystems shaping the entire structure of biomorphic diversity. With this, it is often assumed that "there is the only one single system of ecomorphs" [130] (p. 195), just because there is supposedly the only one global functional structure of the entire biota [130-131]; this idea ascends evidently to the Humboldtian monistic natural-philosophy. However, according to another point of view, it may make sense to develop different biomorphic classifications in which the same organisms can be allocated to different taxa [134-136]. All this seems to be similar in a degree to distinguishing between "general purpose" and "special purpose" classifications in the phenetic program (see section 3.1) and means certain balance between taxonomic monism and pluralism within the biomorphics.

The program under consideration, by elaborating its biomorphic classifications, is of importance for synecology by accentuating on some significant aspects of the structure of the natural ecosystems. The biomorphs recognized in such classifications relate in a certain way to classifications of syntaxa considered, according to one of the synecological conceptions, as fundamental units of that structure [137]. From the other hand, properly construed biomorphic classifications provide very significant information for analyses of interrelation between structures of phylogenetic and biomorphic aspects of the biodiversity, as they are shaped in the course of the biological evolution.

\subsection{The biosystematic program}

The term "biosystematics" has two meanings. On the one hand, it is sometimes used to refer to the entire biological systematics; it is simply an abbreviation of these two words. On the other hand, this is one of the research programs in systematics dealing predominantly with the study of species and intraspecific diversity. Here, this term is used in the second sense.

Biosystematics thus understood appeared to be one of two main programs, along with the phylogenetics (see the next section), implementing evolutionary idea in the biological systematics [138]. Its title biosystematics was meant to emphasize its main concern to the living natural populations, and not to the dead museum specimens, and it became probably the first to have been officially called the evolutionary systematics [139]. Its principal conceptual source was the classificatory Darwinism of the second half of the 19th century, which was emphasized by calling it Darwinian systematics [140]. Accordingly, the beginners of this program declared persistently that the main lower taxonomic units are not "Linnaean species" but geographic races, which are the only natural biological entities deserving explorations and classification (138,140-144]; the term population systematics directly indicated the level in the taxonomic hierarchy it deals with [145]. At last, to stress a novelty of this program against the "orthodox" one, it was termed "The new systematics" [144-148]. 
Emergence of this taxonomic theory and program appeared to be, along with the phenetics (see section 3.1 on it), a response of the biological systematics to the challenges of the positivist philosophy of science. No less (if no more) important role in its shaping played an active formation of the "new biology" of the beginning of the 20th century with its interest in ecology, physiology, genetics and, of course, in its efforts to explain everything by evolutionary mechanisms acting at population level. Biosystematics absorbed new ideas and facts with considering them from a standpoint of evolution of populations; due to this, it played an important role in formation of an evolutionary concept called the "Great Synthesis" in the 1930-40s [12,148].

According to specific understanding of its tasks, biosystematics (together with phenetics) abandoned general idea of the global Natural System - for a simple reason that supraspecific systematic categories have been excluded from its particular Umwelt. It is mainly engaged in elucidating the ecological nature and genetic mechanisms of both dynamics and stability of intraspecific categories and units called gene-ecological by G. Turreson [149]. It was emphasized that these biosystematic units and their classifications did not have to coincide with those of the "orthodox" systematics, since they were distinguished on different grounds [150-151]. It was also proposed, in addition to the classification of those units, to fix continuous trends ("clines") of geographic and ecotypic variability of particular characters over the entire ranges of widely distributed species [152-153].

The biosystematic studies focused on comparative analysis of data use all available categories of data to discriminate intraspecific gene-ecological units, thus realizing the phenetic idea. The only significant difference between phenetics and biosystematics, from a taxonomic perspective, is that the former uses only proper traits of organisms (see section 3.1), while the latter plays attention also to their ecological characteristics. This circumstance predictably caused an extensive employment of numerical methods by biosystematics. In addition, within the framework of this program, a special area of research has been formed, namely experimental systematics [154-155], as a kind of another response to the physicalist challenges. It is based on an idea that all judgments on the differentiation of closely related species and intraspecific units should be subject to the experimental verifications under natural and/or laboratory conditions.

Biosystematic research, from the very beginning to the present, have been being most popular in the botany [155-161]. In particular, one of its leaders A. Takhtadzhyan [157] defined it as "a branch of botany studying the taxonomic and population structure of species, its morphological, geographical, ecological, and genetic differentiation, origin, and evolution" (p. 331). In zoology, biosystematics (under the name "new systematics") was initially promoted by E. Mayr [145], but later an interest to it almost disappeared [141, 162].

Recent phylogeographics dealing with reconstructions of microphylogenies of widely distributed species [163-165] may have certain concern to the biosystematics issues. However, it restricts itself by the numerical phyletic methods and do not take into consideration other types of data (morphological, ecological, etc.). Therefore its results play but an auxiliary role in the complex biosystematic studies.

Contrary to this, recently developed idea of the integrative systematics, as opposed to the total "molecularization" of research at the species level, can actually be considered a certain revival of the biosystematic theme in zoology. Its main idea is that the delimitation of species units by molecular genetic characters is but an initial stage in the study of the species diversity, the bulk of which should involve analysis of all available characters allowing to consider various aspects of species natural history [166-169].

\subsection{The phylogenetic program}

This program is another version, along with the biosystematics, of the implementation of evolutionary ideas in the biological systematics, in this case at macroevolutionary levels. The first attempt to initiate it was "Philosophy of Zoology" by J.-B. Lamarck at the beginning of the 19th century; it was actually focused on macroevolution, but appeared to be premature. The second attempt was «General Morphology of Organisms» by E. Haeckel in the second half of the 19th 
century, it turned out to be much more successful. One of its principal outputs became "systematic phylogeny" (as Haeckel called it), associated with the historical interpretation of macrotaxa and their characters, it is now commonly known as the phylogenetic systematics.

The main parameters of the Umwelt shaping the ontological basis of the phylogenetic theory and program, in their quite general sense, can be briefly summarized and formalized as follows [170-172]. It is based on an assumption (quasi-axiom) that the ordered diversity of organisms is a result of the global long-term phylogenetic process encompassing biota as a whole. This process involves origin of some groups (descendants) from others (ancestors), the emergence of new groups being accompanied by the emergence of their specific properties (Darwin's formula "descent with modification"). It has divergent (cladogenesis) and directed (anagenesis) components; divergent evolution leads to irreversible decrease in both kinship and similarity, while anagenetic evolution can lead to secondary decrease in similarity in some structures (convergence). Attributes of a newly emerging group of organisms are inherited from its closest common ancestor by its descendants in both conserved and modified forms and make them more similar to each other than to members of other groups (quasi-axiom of inherited similarity). Phylogeny thus understood produces phylogenetic pattern defined as a hierarchy of monophyletic groups of different levels of generality interconnected by kinship (phylogenetic) relationships.

From these basic assumptions it is deduced that the natural classification should be phylogenetic; this means that any particular classification should reflect the structure of the respective phylogenetic pattern as completely as possible. This general idea is implemented by the principle of monophyly: a groupshould be characterized primarily by unity of origin, i.e. should include descendants of a single ancestral form. This principle is crucial for the entire phylogenetic program: only monophyletic group (phylon), characterized by such a unity of origin, is thought to be natural and can be recognized as a taxon of phylogenetic classification. To the contrary, any group that does not meet this criterion is treated polyphyletic and considered artificial in most schools of phylogenetic taxonomy. Accordingly, in elaborating a phylogenetic classification, the most significant characters are those that allow recognizing monophyletic groups.

The main contribution of the phylogenetic program to the development of other branches of biology is that phylogenetic reconstructions provide a sufficiently reliable basis for the historical interpretations of similarities and differences between organisms by any kinds of their traits. One of instruments of such interpretation is detection of the so called "phylogenetic signal" in the overall pattern of similarity relations.

This program has been dominating in the biological systematics since the mid-19th century. It had been represented first by what can be reasonably termed classical (Haeckelian) phylogenetics; two other main versions (subprograms) were added to it in the mid-20th century, namely evolutionary taxonomy and cladistics. These subprograms differ basically in their treatments of the phylogenetic process (less or more reductional), the relations between phylogenetic pattern and phylogenetic classification (less or more strict), and the methods of elaborating the latter (selection of characters, assessment of similarity, ranking taxa, etc.). Another important difference between them is determined by two particular interpretations of the principle of monophyly, which can be treated either "narrow" or "broad". In the first case (holophyly), a group is considered monophyletic if it includes all descendants of the same ancestor, the latter being treated obligatory as a species. In the second case (paraphyly), a monophyletic group includes only a part of the descendants of the same ancestor, which may be a supraspecific group. The groups defined accordingly to these two versions of monophyly are termed holo- and paraphyletic, respectively. By all these features, the classical (Haeckelian) phylogenetics and evolutionary taxonomy are close to each other, while cladistics is most specific.

The classical phylogenetic subprogram equally takes into account both cladogenetic and anagenetic components of phylogeny, though does not place a particular emphasis on the adaptive nature of evolution. Evolutionary changes are considered mainly as transformations of structural plans of organisms, according to which their groups are interpreted as various "implementations" of such plans. So of great importance is reconstructions of the ancestral body plans, which makes Haeckelian approach a phylogenetic interpretation of the structural typology [97] (see section 3.4 on the latter). 
The geological time of existence of the groups is quite significant; earlier organisms are perceived as "potential" ancestors of more recent ones. The phylogenetic tree in its classical interpretation has a rather complicated configuration: it is "tied" to the geochronological scale and shows sequence of divergence, time of existence and dynamics of diversity of the monophyletic groups, as well as successive stages of transformations within respective prevailing anagenetic trends (such as "arthropodisation", "mammalisation", "angiospermisation", etc.).

An emphasis on body plans implies that the monophyletic groups are characterized by commonality of both conservative and innovative characters, with some of the latter can be acquired as a result of parallel evolution. Accordingly, monophyly is understood as "broad", so both holophyletic and paraphyletic groups are equally significant in the phylogenetic classifications of this kind. The main argument in favor of the reality of paraphyletic groups is that they do not lose their morphobiological specificity after cleavage of "side branches" from them by developing their own novel specializations [173-178]; examples are bryophytes and vascular plants, actinopterygians and tetrapods, archosaurian reptiles and birds, artiodactyls and cetaceans, etc.

The correspondence between the phylogenetic tree and a classification based on it is admitted to be "soft": it is sufficient that the latter should be just compatible with the branching structure of the tree and should not contain evidently polyphyletic taxa. Accordingly, the tree being converted into classification can be "cut" in different fragments both "vertically" and "horizontally" to reflect most adequately both kinship relations and anagenetic specificity of the monophyletic groups. Therefore, generally speaking, the same phylogenetic tree can equally be represented by several phylogenetic classifications different in some details. The hierarchy of phylogenetic classification in its classical interpretation is ranked.

The evolutionary taxonomy subprogram was thus designated by its "founding father" G. Simpson [179] in order to demarcate it terminologically from the evolutionary systematics in its biosystematic interpretation (see previous section). This phylogenetic subprogram resembles the classical one by most of its key presumptions; its specificity is determined by a great attention paid to the adaptive essence of the evolutionary process, with the concept of adaptive zone playing especially important role [180]. The adaptive zone is defined as a set of environmental conditions that determines the general type of adaptation of organisms; with this, it is assumed that morphophisiological specificity of a group is a result of similar reaction of organisms with similar epigenetic organization, inherited from their common ancestor, to similar environmental conditions. According to this evolutionary model, acquisition of basic "adaptative syndrom" of a taxon due to parallel evolution of its members witnesses its evolutionary unity no less than the inherited features. Thus, taxonomic integrity is defined by three interrelated evolutionary parameters: the unity of origin (monophyly in its broad sense), the unity of morphobiological organization (anagenetic grade), and the unity of evolutionary trends (parallelisms) [179, 181,182]. In arranging phylogenetic classifications, an auxiliary principle of decisive gap is introduced, according to which levels of mutual distinctiveness of taxa should be taken into consideration in their both individuation and ranking.

The cladistic subprogram, in contrast to two just considered, is based on a drastically simplified representation of phylogeny, which is reduced to cladogenesis, and on respectively simplified interpretation of both phylogenetic relations and phylogenetically significant similarity. The "founding fathers" of this version (V. Zimmermann, W. Hennig) designated their approach as phylogenetic systematics [183-186] and this designation currently dominates [170,172,187,188], sometimes it is equalized with the entire biological systematics [189-191]. However, as it will be shown below, its differences from the other two phylogenetic programs just considered are so significant that the term "cladistics" proposed by E. Mayr [192] is more than justified (though seems to be nearly forgotten).

In cladistics, phylogenetic tree is reduced to a fairly simple cladogram, and monophyly is refined to holophyly. The phylogenetic (more correctly, cladistic) unity was determined initially through a cladistic relationship as follows: two groups $\mathbf{A}$ and $\mathbf{B}$ are closer to each other than to a group $\mathbf{C}$ if the closest common ancestor of $\mathbf{A}$ and $\mathbf{B}$ is more recent than the common ancestor of all three groups. In an afterward version currently dominating, this relationship is determined by reference not to a hypothetical ancestors, but to some real remote group: two groups $\mathbf{A}$ and $\mathbf{B}$ 
constitute a holophyletic group if it is shown that they are "sister" relative to a third group C "external" to them (routinely called an outgroup). Thus, the concept of ancestor, and with it the geological time scale also, are paradoxically excluded from the Umwelt of this branch of the phylogenetics.

At operational level, the principle of synapomorphy is introduced to reveal hierarchy of sister groups, according to which the holophyletic group is determined only by synapomorphies, i.e. by similarities in apomorphic (uniquely derived) characters, while simplesiomorphy (similarity in ancestral and "parallel" characters) is not taken into account. This principle makes cladistic theory very peculiar with respect to its logic $[12,170,193]$. In all other classificatory approaches, the two-state (Aristotelian) division logic dominates, in which judgments of " $\mathrm{A}$ " and "non- $\mathrm{A}$ " types are equally significant for identifying taxa. In the cladistics, one-state logic of N. Vasil'ev [194,195] actually operates: only judgments of type " $\mathrm{A}$ " (synapomorphies) are significant, while judgments of type "non-A" (non-synapomorphies = simplesiomorphies) are insignificant for recognition of holophyletic taxa. In addition, the above principle means that, for delineation of a holophyletic group, only its "inner" similarity is significant while its "outer" differences from other taxa are insignificant; thus these two components of general similarity relations - similarity and difference-turn out to be logically "asymmetric" with respect to their classificatory function. For this reason, the above principle of decisive gap is not relevant in the cladistics. Finally, the principle of synapomorphy replaces the typological component of classical phylogenetics with a variant of phenetic combinatorics of characters: a cladon is identified more reliably, if it is diagnosed with a larger number of synapomorphies ("the more characters, the better").

Cladistic classification is based on the strict correspondence between the hierarchy of sister groups in a cladogram and the hierarchy of taxa in respective classification. For this, the initial cladogram is cut "vertically" only, with all "horizontal" relations being discarded, which provides recognition of cladistically consistent taxa (cladons). This is complemented with the principle of sister groups equal ranking: the groups descending to the same node (branching point) of a cladogram are treated in respective classification as the taxa of the same rank. As a result, the ranked hierarchy of cladistic classifications for large diverse groups becomes very fractional and non-operational. This eventually led to a suggestion to abandon fixed ranks from the hierarchy of cladistic classifications and to make them rankless [5,37,196-198].

General position of the cladistics regarding ontological status of the holophyletic groups is declared quite realistic [183-185]. However, as it was emphasized above (see sections 2.1), the more reduced is the Umwelt shaping ontological basis of a particular taxonomic theory, the less portion of objective reality of the original Umgebung it contains. This conclusion is obviously true in case of cladistics: it is based on quite reductional representation of phylogeny and therefore is less "realistic" in comparison with both classical phylogenetics and evolutionary taxonomy.

In the contemporary phylogenetic studies of the extant organisms, an approach called molecular phylogenetics $(=$ phylogenomics $=$ genophyletics $)$ takes a leading position. It includes analysis of DNA or/and RNA nucleotide sequences, assessment of the similarity between organisms by these sequences, and construction of molecular phylogenetic trees based on this similarity; all these procedures employ numerical techniques, which makes numerical phyletics (see section 3.3) an instrumental part of the molecular phylogenetics. Transformation of molecular phylogenetic trees into classifications in practical studies strongly follows the above principles of the cladistics, so the molecular phylogenetics, from a taxonomic standpoint, can rightly be considered as a part of the cladistic subprogram. Therefore, its taxonomic application is called sometimes genosystematics $[12,199,200]$, though it might be more correct to call it genocladistics.

It is curious enough that the most recent development of the phylogenetic systematics means that the history of this biological discipline makes a kind of circle by returning to that stage when the scholastic genus-species scheme dominated $[12,38]$. One feature of this return is signified by an idea of rankless cladistic classifications, another by using molecular genetic data exclusively for inferring these classifications, which revives something like a unified division basis.

According to the original intention of the cladism ideologists, their approach should be common for all living beings. This intention is implemented by the universal "Tree of Life" project 
[201]. However, as the recent results show, the hope for a universal "cladification" (see [140] for this term) of the living matter is hardly warranted. The reason is that the basal fragment of the phylogenetic tree, shaped by branching patterns of the prokaryote taxa, is not strictly divergent but rather a net-like [202]. This obstructs elaboration of strictly "vertical" classifications cladistics seeks to achieve.

Nowadays, a conviction is gradually spreading among systematic theoreticians that cladistics, especially with its "molecular appendage", is too reductional to reflect adequately the structure of taxonomic diversity, even if the latter is simplified to being treated phylogenetically. This is reflected in the appearance of publications speculating on possible developments of the biological systematics "beyond cladistics" [203-205]. However, currently cladistic approach is actively developed at the methodological level and still dominates in the practical systematic research.

\subsection{In a shade of dominant: The evo-devo program?}

Generally speaking, this research program is just beginning to take shape and is poorly noticeable against the nowadays dominating cladistics based on the analysis of molecular genetic data [38]. Its specificity is in that it focuses on the evolutionarily interpreted variety of ontogenetic patterns of multicellular organisms [206-207]. The basis for this is provided by a synthesis of the just considered phylogenetics in its rather widened sense, epigenetic typology (see section 3.4 on it), and the evo-devo concept, which is an abbreviation for the evolutionary developmental biology considering patterns and mechanisms of the evolution of ontogeneses [208-213]. The concepts of dynamic archetype (phylocreod) and phylotype (phylotypic stage) mentioned above (see section 3.4) fit well into general context of this taxonomic theory: the first means a stable (canalized) trajectory of the evolutionary development of the ontogenetic patterns, the second refers to those patterns that are initial for particular phylocreods and which changes lead to "switching" from one phylocreod to another mainly due to changes in composition and function of the regulatory genes.

From a historical perspective, this concept goes back to the classical principle of "triple parallelism" of the mid-19th century: it links a) distribution of the body plans of organisms in the Natural System, b) sequence of appearance of organisms with various body plans in geochronlogy, and c) successions of ontogenetic stages in the individual development of those organisms. The fundamental novelty of the evo-devo concept is that it focuses on the genetic mechanisms of regulation of ontogenesis.

As it can be seen, the evo-devo (or phylo-evo-devo) taxonomic theory and respective research program are based on a rather rich biologically meaningful ontology, which distinguishes it positively from quite reductional cladistics and molecular phylogenetics. As noted above (see beginning of section 3), this means another, newest version (along with biomorphics and evolutionary taxonomy) of the contemporary "biologization" of the systematics. At the same time, as far as phylogeny is considered as one of two cornerstones of this program, it is possible to consider the latter as another branch of the phylogenetic program in its widest sense.

By focusing on the evolution of the ontogenetic patterns and the epigenetic mechanisms ensuring their historical stability and dynamics, this research program brings its own version of representation of historical patterns of biodiversity and respective classifications. The former can be represented by a phylo-ontogenetic tree, which is actually a phylogenetically interpreted "Baerian" tree (see section 3.4 on the latter). This tree is transformed into corresponding evo-devo classification in the same manner as the phylogenetic one, with its ranking scale being derived from a sequence of appearance of respective ontogenetic patterns in the evolution of multicellular organisms. The main characteristics of an evo-devo taxon becomes its specific ontogenetic pattern as a whole dynamic system not reducible to any particular developmental stages [103-105,207]. This allows systematics not only to deprive a pure molecular basis of the classification of its priority status but also to overcome a kind of traditional "adultocentrism" in the consideration of organismal anatomy [212].

Obviously, the evo-devo research program is not universal. Its application is limited to the groups of multicellular organisms with sufficiently developed ontogenetic cycles. Accordingly, many protists and apparently all prokaryotes appear to be outside the scope of its competence. 
However, this circumstance should hardly be considered as a serious disadvantage: as it was emphasized above (see section 2.2), any research program in the systematics - more precisely, each particular taxonomic theory underlying it-is inevitably "local" with regard to its applications.

From an epistemological viewpoint, the research program under consideration faces a serious problem caused by its rich natural ontology. The latter presumes that elaboration of evo-devo classifications should be based on a joint exploration of two complexly interacting multifaceted dynamic systems, viz. phylogeny and ontogeny [106,214,215]. In such a knotty cognitive situation, the so-called NP-completeness problem becomes quite relevant (see [216-217] on it). It means that the more complicated are initial conditions of certain research task, the less likely it becomes to find its most optimal solution. In the case of systematics it means a low probability to attain to a classification most optimally representing specific multifaceted Umwelt shaped by evolutionary interpreted diversity of ontogenetic patterns $[12,170]$. Therefore, elaboration of the "evo-devo natural" classifications turns out to be significantly more troublesome as compared to, say, cladistically consistent. Though, this problem is true for the evolutionary taxonomy (see previous section on it), as well, as it deals also with a very rich natural ontology.

At the moment, classifications realizing most consistently the evo-devo taxonomic theory and thus belonging to the program in question are very few (e.g. [104,217,218]; some more could be found in the festschrifts on evo-devo cited above). The reason is that detailed studies on diversity and evolution of the mechanisms of regulation of ontogenesis in animals and plants on the modern epigenetic basis are just beginning and therefore, as it always occurs with new disciplines, involve analyses of not numerous "model" organisms. Therefore it seems premature to consider how actively this research program will be developing and how productive it may turn out to be for the systematics, how serious alterations of the taxonomic classifications it may cause, and which particular such alterations can and will be. Among the main tasks to be solved by the evo-devo taxonomic theory to make the program in question more promising, seem to be the following: a) elaboration of a calculus for assessment of relative significance ("weight") of differences in molecular sequences and ontogenetic rearrangements, b) elaboration of general ranking scale for the evo-devo classifications of different groups of organisms, and c) development of an optimal way to combine "vertical" and "horisontal" interrelations between the groups with different ontogenetic patterns to reflect most adequately their both primitive (ancestral) and advanced features.

\section{Conclusion: How to handle the taxonomic pluralism}

As it was emphasized at the very beginning of this article, the scientific pluralism is supported by the contemporary non-classical philosophy of science. Nevertheless, the classical scientific monism is also quite popular, and not only in academic circles but also (perhaps even more) among practitioners. Thus, the problem of confronting scientific pluralism and monism is more than relevant.

One of the main practical outputs of the taxonomic pluralism at a theoretical level (multiplicity of taxonomic theories) is that it produces the taxonomic pluralism at an empirical level (multiplicity of classifications for particular groups). The latter means that the same organisms can rightfully be allocated to different taxa in classifications based on different taxonomic theories. However, various users of the taxonomic classifications wish evidently to get a unified and stable list of taxa and do not intend to puzzle out differences between particular theories and research programs. So they uniformly "vote" for the taxonomic monism by supposing there is actually only one "natural" pattern of the taxonomic diversity reflecting into only one "natural" classification available for a unified direct application in various applied projects.

In this connections, an important question arises as to how "limited" can and should be the taxonomic pluralism $[219,220]$. Such a standpoint of a "limited pluralism" presumes implicitly that there are "good" and "bad" taxonomic theories, so this question actually is as to how to "separate the clean from the unclean" and to eliminate somehow the latter. There are several possible approaches to answer it. 
The simplest and straightforward one is offered by a pragmatic perspective, according to which the main evaluating criterion for a taxonomic theory is a possibility to convert it into an operational concept most effective in resolving certain practical tasks. Such theory deserves being developed by providing a support to respective taxonomic community elaborating it, while others are doomed to elimination just because of restricted resources for systematic studies. Quite demonstrative case in this respect is recent short but hot discussion of instability (plurality) of species classifications to be used for the conservation purposes [221-223]. It illustrates how such a "scientific Darwinism" may turn disagreement of scientific ideas into an administrative struggle for the limited resources, which, in the most recent times, is promoted indirectly by the system of grant support for scientific activity [224].

Another approach, of an epistemological kind, appeals to scientific consistency of a taxonomic theory that has to correspond to certain criteria allowing to distinguish scientific knowledge from others (religious, commonplace, etc.). In particular, it is presumed that such theory should make it possible to elaborate testable scientific hypotheses about structure of taxonomic diversity. The problem here is that such criteria vary with evolution of the philosophy of science, so the theories consistent from one standpoint may appear to be inconsistent from another. Several decades ago numerical phenetics pretended to be both most scientifically consistent and effective and struggled against phylogenetics [43] - and where is it now?

At last, it is possible to consider this question from a metaphysical standpoint, accordingly to which the best taxonomic theories are those that are substantiated by reference to the natural causes structuring biota and thus are biologically meaningful enough (see section 2.1). From such a perspective, a preference should be given to the theories with well-developed "natural" ontologies modeling multi-faceted taxonomic diversity as completely as possible. From this standpoint, any episto-rational theories (see section 3.2 on these) are least relevant, whereas, among ontology-based theories, those developed by evolutionary taxonomy and evo-devo research programs seem to be more consistent and effective as compared to, say, a more reductional cladistics (especially in its genosystematic version).

At any rate, from a scientific perspective, any artificial culling of some research programs in favor of others, by declaring the latter having a privileged status for various reasons, contradicts the fundamental principle of the freedom of scientific activity. So the only serious limitation on a "rampant" pluralism of taxonomic theories seems to be imposed by the very most important task of the biological systematics - to produce biologically sound classifications representing comprehensively multi-faceted diversity of the living matter. Those theories that provide such a possibility are "good", while those that do not are "bad". With this, it should be borne in mind that such categorization of taxonomic theories is not be taken as universal; instead, they may appear to be either "good" or "bad" locally. This is because the structure of diversity in different groups of organisms can be formed by different causal factors, therefore most pertinent (locally "good") to them will be different partial taxonomic theories.

Facing irreducible multiplicity of research programs in the biological systematics, another and a more relevant question seems to come to the fore $[12,19]$. It can be posed such a way: how to combine different classifications, each reflecting a particular manifestation of the entire taxonomic diversity, in order to get a whole picture of the latter? As it was indicated above (see section 2.1), it seems to be hardly possible to elaborate a biologically sound general reference system in the form of some "integrated" or "omnispective" classification. So, one of the possible answers to this question may be an appeal to develop something like faceted classification (in sense of [225]). It would probably allow, for each group of organisms and eventually for the entire "Tree of Life", to combine different particular classifications based on different taxonomic theories into a single pool. In this connection, one of the most actual tasks of the general taxonomic theory would become elaboration of an appropriate meta-language with an exhaustive natural (non-formal) ontology uniting those developed by different particular theories.

\section{Funding}


This contribution was supported by the Governmental Theme no. AAAA-A16-116021660077-3.3 implemented by the Research Zoological Museum, Lomonosov Moscow State University.

\section{Acknowledgments}

The author is sincerely grateful to Prof. Alessandro Minelli for having invited me to contribute to the special issue on "Renegotiating Disciplinary Fields in the Life Sciences" and for commenting on a draft version of this contribution.

\section{Conflicts of interest}

The author declares no conflict of interest.

\section{References}

1. Hempel, G. Aspects of scientific explanation and other essays in the philosophy of science. Free Press: New York, NY, USA. 1965; ISBN 978-0-0291-4340-7

2. Rosova, S.S., Ed. Towards a theory of classification. Novosibirsk University Press: Novosibirsk, RF, 1995; ISBN 5-88742-004-9. (in Russian)

3. Jacobus, L.A. Sudden apprehension: Aspects of knowledge in Paradise lost. Mouton: The Hague, NL, 1976; ISBN 978-9-0279-3253-2.

4. Kellert, S.H., Longino H.E., Waters, C.K. Eds. Scientific Pluralism. University of Minnesota Press: Minneapolis, MN, USA, 2006; ISBN 978-0-8166-4763-7.

5. Ruse, M. The philosophy of biology. Hutchinson University Press: London, GB, 1973; ISBN 978-0-0911-5221-5.

6. Hull, D.L. Science as a process. University Chicago Press: Chicago, IL, USA, 1988; ISBN 978-0-2263-6050-8.

7. Mahner, M., Bunge, M. Foundations of biophilosophy. Springer Verlag: Frankfurt, DE, 1997; ISBN 978-3-6620-3368-5.

8. Ereshefsky, M. The poverty of the Linneaean hierarchy: A philosophical study of biological taxonomy. Cambridge University Press: New York, NY, USA, 2001; ISBN 978-0-5210-3883-6.

9. Richards, R.A. The species problem: A philosophical analysis. Cambridge University Press: New York, NY, USA, 2010; ISBN 978-0-521-19683-3.

10. Wilkins, J.S. Species: A history of the idea. University California Press: Berkely, CA, USA, 2010; ISBN 978-0-520-26085-6.

11. Ruphy S. Scientific pluralism reconsidered. A new approach to the (dis)unity of science. University of Pittsburgh Press: Pittsburgh, PA, USA, 2016; ISBN 978-0-8229-4458-4.

12. Pavlinov, I.Ya. Foundations of biological systematics: History and theory. KMK Scientific Press. Moscow, RF, 2018; ISBN 978-5-6040-7499-2. (in Russian, with English content)

13. Mayr, E. Numerical phenetics and taxonomic theory. Syst. Zool. 1965, 14, 73-97, DOI:10.2307/2411730.

14. Hull, D.L. Contemporary systematic philosophies. Annu. Rev. Ecol. Evol. Syst. 1970, 1, 19-54, DOI:10.1146/annurev.es.01.110170.000315.

15. Pesenko, Yu.A. Methodological analysis of systematics. I. Formulation of the problem, and principal taxonomic schools. In Principles and methods of zoological systematics; Zoological Institute: Leningrad, 1989; ISBN 978-7925-0216-1. (in Russian, with English summary)

16. Mayr, E. Toward a new philosophy of biology. Cambridge University Press: New York, NY, USA, 1988; ISBN 978-0-6748-9666-6.

17. Woodger, J.H. The axiomatic method in biology. Cambridge University Press: Cambridge, GB, 1937.

18. Gregg, J.R. The language of taxonomy. Columbia University Press: New York, NY, USA, 1954.

19. Pavlinov, I.Ya. How it is possible to elaborate taxonomic theory. Zool. Issled. 2011, 10, 45-100, ISSN 1025-532x. (in Russian, with English summary) 
20. von Uexküll, J. The theory of meaning. In Essential readings in biosemiotics. Anthology and commentary; Favareau, D., Ed.; Springer Science + Business Media: Dordrecht, NL, 2010; pp. 81-114; ISBN 978-1-4020-9649-5.

21. Kull, K. Umwelt and modelling. In The Routledge companion to semiotics. Cobley, P. (ed.). Routledge: London, GB, 2009; pp. 43-56.

22. Knyazeva, E.N. J. von Uexküll's Concept of Umwelt and its Significance for the Modern Epistemology. Vopr. Filos. 2015, 5, 30-44, E-ISSN 2414-0856. (in Russian, with English summary)

23. Chase, J. M.; Leibold M. A. Ecological niches: Linking classical and contemporary approaches. University of Chicago Press, Chicago, IL, USA, 2003. ISBN 978-0-2261-0180-4.

24. 24. Wartofsky, M. W. Models: Representation and scientific understanding. Reidel: Dordrecht, NL, 1979.

25. Gilmour, J.S.L. Taxonomy and philosophy. In The new systematics; Huxley, J., Ed.; Oxford University Press: Oxford, GB, 1940; pp. 461-474.

26. Voyshvillo, E.K. Concept as a form of thinking: Logical and epistemological analysis.: Moscow State University Publ.: Moscow, RF, 1989. (in Russian)

27. Kosko, B. Fuzzy thinking: The new science of fuzzy logic. Hyperion: New York, NY, USA, 1993; ISBN 978-0-0065-4713-6.

28. Lyubarsky, G.Yu. Origins of hierarchy: The history of taxonomic rank. KMK Science Press: Moscow, RF, 2018; ISBN 978-5-9500-8296-2. (in Russian)

29. de Beer, G. Homology, an unsolved problem. Oxford University Press: Oxford, GB, 1971.

30. Hall, B.K., Ed. Homology: The hierarchical basis of comparative biology. Academic Press: New York, NY, USA, 1994; ISBN 978-0-1231-8920-2.

31. Bock, G.R.; Cardew, G.; Eds. Homology. John Wiley \& Sons: Chichester, GB, 1999; ISBN 978-0-1231-9583-8.

32. Pavlinov, I.Ya. The contemporary concepts of homology in biology: A theoretical review. Biol. Bull. Rev. 2012, 2, 36-54, DOI:10.1134/S2079086412010057.

33. Wilson, R.A.; Ed. Species: New interdisciplinary essays. The MIT Press: Cambridge, MA, USA, 1999; ISBN 978-0-2627-3123-2.

34. Hey, J. Genes, categories, and species. The evolutionary and cognitive cause of the species problem. Oxford University Press: New York, NY, USA, 2001; ISBN 978-0-1951-4477-2.

35. Stamos, D.N. The species problem. Biological species, ontology, and the metaphysics of biology. Lexington Books: Oxford, GB, 2003; ISBN 978-0-7391-0778-2.

36. Pavlinov, I. Ya. ed. The species problem: Ongoing issues. InTech Open Access Publ.: Rijeka, 2013; ISBN 978-953-51-0957-0.

37. Zachos, F.E. Species concepts in biology. Historical development, theoretical foundations and practical relevance. Springer: Basel, CH, 2016; ISBN 978-3-3194-4966-1.

38. Pavlinov, I.Ya. Biological systematics: In search of the Natural System. KMK Scientific Press: Moscow, RF, 2019; ISBN 978-5-907099-95-1. (in Russian)

39. Atran, S. The cognitive foundations of natural history: Towards an anthropology of science. Cambridge University Press: New York, NY, USA, 1990; ISBN 978-0-5213-7293-0.

40. Berlin, B. Ethnobiological classification: Principles of categorization of plants and animals in traditional societies. Princeton University Press: Princeton, New Jersey, NJ, USA, 1992; ISBN 978-0-6910-9469-4.

41. Sokal, R.R.; Sneath, R.H.A. Principles of numercial taxonomy. W.H. Freeman \& Co: San Francisco, California, CA, USA, 1963.

42. Sneath, R.H.A.; Sokal, R.R. Numercial taxonomy. The principles and methods of numerical classification. W.H. Freeman \& Co: San Francisco, California, CA, USA, 1973; ISBN 978-0-7167-0697-7.

43. Winsor, M.P. 2004. Setting up milestones: Sneath on Adanson and Mayr on Darwin. In Milestones in systematics; Williams, D.M., Forey, P.L., Eds.; CRC Press: Boca Raton, FL, USA; pp. 1-18, 978-0-4152-8032-7. 
44. Nelson, G. Cladistic analysis and synthesis: principles and definitions, with a historical note on Adanson's Familles des Plantes (1763-1764). - Syst. Zool. 1979, 28, 1-21, DOI:10.1093/sysbio/28.1.1.

45. Goodman, N.. Seven strictures on similarity. In Problems and Projects; Bobs-Merrill: Indianapolis, IN, USA, 1972; pp. 437-446. ISBN 978-0-8144-1682-2.

46. Tversky, A. Features of similarity. Psychol. Rev. 1977, 84, 327-352, DOI:10.1037/0033-295X.84.4.

47. Sober, E. Philosophy of biology, 2nd ed. Westview Press: Boulder, CO, USA, 2000; ISBN 978-0-8133-4065-4.

48. Rieppel, O.; Kearney, M. Similarity. Biol. J. Linn. Soc. Lond. 2002, 75, 59-82, DOI:10.1046/j.1095-8312.2002.00006.x.

49. Kluge, A.G. Total evidence or taxonomic congruence: Cladistics or consensus classification. Cladistics 1998, 14, 151-158, DOI:10.1006/clad.1997.0056.

50. Rieppel, O. The language of systematics, and the philosophy of "total evidence". Syst. Biodivers. 2004, 2, 9-19, DOI:10.1017/S147720000400132x.

51. Rieppel, $\mathrm{O}$. The philosophy of total evidence and its relevance for phylogenetic inference. Pap. Avulsos Zool. (Sao Paulo) 2005, 45, 77-89, DOI:10.1590/S0031-10492005000800001.

52. Swoyer, C. Conceptualism. In Universals, concepts, and qualities: New essays on the meaning of predicates; Trawson, E.S, Chakrabarti, A., Eds.; CRC Press: Routledge, GB, 2006; pp. 127-154, ISBN 978-0-7546-5032-4.

53. Newton-Smith, W.H. 1981. The rationality of science. Routledge \& Kegan Paul Ltd: Abingdon, GB; ISBN 0-203-04615-3.

54. Gaydenko, P.P. Scientific rationality and philosophical mind. Progress-Traditsia: Moscow, RF, 2003; ISBN 5-89826-142-7.

55. Pavlinov, I.Ya. Concepts of rational taxonomy in biology. Biol. Bull. Rev. 2011, 1, 60-78, DOI:10.1134/S2079086411030078.

56. Lyubishchev A.A. Problems of the form, system, and evolution of organisms. Nauka: Moscow, RF, 1982; p. 164. (in Russian)

57. Stevens, P.F. Haüy and A.-P. Candolle: Crystallography, botanical systematics, and comparative morphology, 1780-1840. J. Hist. Biol. 1984, 17, 49-82, DOI:10.1007/BF00397502.

58. Drouin, J.-M. Principles and uses of taxonomy in the works of Augustin-Pyramus de Candolle. - Stud. Hist. Philos. Biol. Biomed. Sci. 2001, 32, 255-275, DOI:10.1016/S1369-8486(01)00002-4.

59. Driesch, H. The science and philosophy of the organism. Aberdeen University Print: Aberdeen, GB, 1908.

60. Meyen, S.V., The main aspects of typology of organisms, Zh. Obshch. Biol. 1978, 39, 495-508, ISSN 0044-4596. (in Russian, with English summary)

61. Quine, W.V. Natural kinds. In Naming, Necessity and Natural Kinds; Schwartz, S., Ed.; Cornell University Press: Ithaca, NY, USA, 1994; ISBN 978-0-8014-9861-9, pp. 155-175.

62. Popov, I.Yu. "Periodical systems" in biology (a historical issue). Verhandl. Gesch. Theor. Biol. 2002, 9, 55-69, ISBN 978-3-8613-5388-1.

63. Popov, I.Yu. Periodical systems and a periodical law in biology. KMK Science Press: Moscow, RF, 2008; ISBN 978-5-8731-7505-5. (in Russian, with English summary)

64. Salthe, S. Development and evolution: Complexity and change in biology. The MIT Press, Cambridge, MA, USA, 1993; ISBN 978-0-2621-9335-1.

65. Giampietro, M. Complexity and scales: The challenge for integrated assessment. Integr. Assess. 2002, 3, 247-265, DOI:10.1076/iaij.3.2.247.13568.

66. Ho, M.W. How rational can rational morphology be? A post-Darwinian rational taxonomy based on a structuralism of process. Theor. Biol. Forum 1988, 81, 11-55, ISSN 2282-2593.

67. Ho, M.W. An exercise in rational taxonomy. J. Theor. Biol. 1990, 147, 43-57, DOI:10.1016/s0022-5193(05)80251-6.

68. Ho, M.W.; Saunders, P.T. Rational taxonomy and the natural system - segmentation and phyllotaxis. In Models in phylogeny reconstruction; Scotland, R.W., Siebert, D.J., Williams, D.M., Eds.; Clarendon Press: Oxford, GB, 1994; pp. 113-124, ISBN 978-0-1985-4824-9.

69. Adanson, M. Familles des plantes. Vincent: Paris, FR, 1763. 
70. Thompson, W.R. The philosophical foundations of systematics. Canad. Entomol. 1952, 84, 1-16, ISSN 0008-347X.

71. Pokrovsky, M.P. Introduction to the classiology. Institute of Geology \& Geochemistry: Ekaterinburg, RF, 2014; ISBN 978-5-94332-108-5. (in Russian)

72. Shuman, A.N. Philosophical logic: Origins and evolution. EkonomPress: Minsk, BY, 2001; ISBN 985-6479-26-6. (in Russian)

73. Russell, G. Logical pluralism. In The Stanford encyclopedia of philosophy, Summer 2019 ed.; Zalta, E.N., Ed.; 2019; https://plato.stanford.edu/archives/sum2019/entries/logical-pluralism/.

74. Griffiths, G.C.D. On the foundations of biological systematics. Acta Biotheor. 1974, 23, 85-131, DOI:10.1007/BF01556343.

75. Gorham, G.; Hill, B.; Slowik, E.; Waters, C. K. 2016. The language of nature: Reassessing the mathematization of natural philosophy in the seventeenth century. University of Minnesota Press, Minneapolis, MN, USA; ISBN 978-0-8166-9989-6.

76. Barsanti, G. La scala, la mappa, l'albero: immagini e classificazioni della natura frasei e ottocento. Sansoni: Florence, IT, 1992; ISBN 978-8-8383-1384-4.

77. Strickland, H.E. On the true method of discovering the natural system in zoology and botany. Ann. Mag. Nat. Hist., Ser. 5, 1841, 6, 184-194.

78. Smirnov, E.S. On construction of systematic categories. Russ. Zool. J. 1923, 3, 358-389. (in Russian)

79. Dunn, G.; Everitt, B.S. An introduction to mathematical taxonomy. Cambridge University Press: New York, NY, USA, 1982; ISBN 978-0-4864-3587-9.

80. Sterner, B.. Well-structured biology: Numerical taxonomy's epistemic vision for systematics. In Patterns in nature; Hamilton, A., Ed.; University of California Press: Berkley, CA, USA, 2014; pp. 213-244, ISBN 978-0-7565-0246-1.

81. Quicke, D.L.J. Principles and techniques of contemporary taxonomy. Chapman \& Hall: London, GB, 1993; ISBN 978-9-4010-4945-0.

82. Abbot, L.A.; Bisby, F.A.; Rogers, D.J. Taxonomic analysis in biology. Computers, models, and databases. Columbia University Press: New York, NY, USA, 1985; ISBN 978-0-2310-4926-9.

83. Swofford, D.; Olsen, G.J.; Waddell, P.J.; Hillis, D.M. Phylogenetic inference. In Molecular systematics, 2 d ed.; Hillis, D.M., Moritz, C., Mable, B.K., Eds.; Sinauer Association: Sunderland, MA, USA, 1996; pp. 407-514, ISBN 0-87893-282-8.

84. Nei, M.; Kumar, S. Molecular evolution and phylogenetics. Oxford University Press: Oxford, GB, 2000; ISBN 978-0-1951-3585-5.

85. Felsenstein, J. Inferring phylogenies. Sinauer Association: Sunderland, MA, USA, 2004; ISBN 978-0-8789-3177-4.

86. Semple, C.; Steel, M. Phylogenetics. Oxford University Press: Oxford, GB, 2003; ISBN 978-0-1985-0942-4.

87. Rieppel, O. The nature of parsimony and instrumentalism in systematics. J. Zool. Syst. Evol. Res. 2007, 45, 177-183, DOI:10.1111/j.1439-0469.2007.00426.x.

88. Shapiro, S. Philosophy of mathematics: Structure and ontology. Oxford University Press: New York, NY, USA, 1997; ISBN 978-0-1951-3930-3.

89. Perminov, V.Ya. Philosophy and foundations of mathematics. Progress-Traditsia: Moscow, RF, 2001; ISBN 5-89826-098-6. (in Russian)

90. Popper, K. Conjectures and refutations: The growth of scientific knowledge. Routledge: London, GB, 2002; ISBN 978-0-7100-6507-0.

91. Gillespie, A., Cornish, F. Intersubjectivity: Towards a dialogical analysis. J. Theor. Soc. Behav. 2010, 40, 19-46, DOI:10.1111/j.1468-5914.2009.00419.x

92. Diekmann, A. Klassifikation, System, 'scala naturae'. Das Ordnen der Objekte in Naturwissenschaft und Pharmazie zwischen 1700 und 1850. Wissenschaftliche Verlag: Stuttgart, DE, 1992; ISBN 978-3-8047-1213-3.

93. Charles, D. Aristotle on meaning and essence. Clarendon Press: Oxford, GB, 2000; ISBN 978-0-1992-5673-0. 
94. Gotthelf, A. Teleology, first principles, and scientific method in Aristotle's biology. Oxford University Press: Oxford, GB, 2012; ISBN 978-0-1992-8795-6.

95. Shatalkin, A.I. Essentialism and typology. In Contemporary systematics: Methodological aspects; Pavlinov, I.Ya., Ed.; Moscow University Press: Moscow, RF, 1996; pp. 23-154, ISBN 978-5-8731-7617-5. (in Russian, with English content)

96. Winsor, M.P. Non-essencialist methods in pre-Darwinian taxonomy. Biol. Philos. 2003, 18, 387-400, DOI:0.1023/A:1024139523966.

97. Naef, A. Idealistische Morphologie und Phylogenetik (Zur Methodik der Systematischen Morphologie). Gustav Fischer: Jena, DE, 1919.

98. Tversky, B. Parts, partonomies, and taxonomies. Develop. Psychol. 1989, 25, 983-995, DOI: 10.1037/0012-1649.25.6.983.

99. Lyubarskii, G.Yu. Archetype, style and rank in biological systematics. KMK Science Press: Moscow, $\mathrm{RF}$, 1996. (in Russian)

100. Oderberg, D.S. Real essentialism. Routledge: Abingdon \& New York, NY, USA, 2009; ISBN 978-0-4158-7212-6.

101. Vasil'eva, L.N. Platonism in systematics. Biology-Soil Institute: Vladivostok, RF, 1992. (in Russian)

102. Ho, M.W. Development, rational taxonomy and systematics. Theor. Biol. Forum 1992, 85, 193-211, ISSN 2282-2593.

103. Orton, G.L. The role of ontogeny in systematics and evolution. Evolution 1955, 9, 75-83, DOI:10.2307/2405359.

104. Martynov, A.V. Ontogenetic systematics, and a new model of Bilaterian evoluiton. KMK Sci. Press. Moscow, RF, 2011; ISBN 978-5-8731-7750-9. (in Russian, with English content)

105. Martynov, A.V. Ontogenetic systematics: The synthesis of taxonomy, phylogenetics, and evolutionary developmental biology Paleontol. J. 2012, 46, 833-864, DOI:10.1134/S0031030112080072.

106. Pavlinov, I.Ya. A critical analysis of A.V.Martynov's version of ontogenetic systematics. Thalassas 2013, 29, 23-33, ISSN 0212-5919.

107. Zakharov, B.P. Transformational typological systematics. KMK Sci. Press. Moscow, RF, 2005; ISBN 978-5-0411-5462-2.

108. Weber, H. Konstrtionsmorphologie. Zool. Jahrb. Abt. Anat. Ontog. Tiere 1958, 68, 1-112, ISSN 0044-5177.

109. Schmidt-Kittler, N.; Vogel, K.; Eds. Constructional morphology and evolution. Springer Verlag: Heidelberg, DE, 1991; ISBN 978-3-6427-6156-0.

110. Beklemished, V.N. Methodology of systematics. KMK Scientific Press. Moscow, RF, 1994, ISBN 5-8731-7005-3.

111. Shatalkin, A.I. Problem of archetype and contemporary biology. Zh. Obshch. Biol. 2002, 63, 275-291, ISSN 0044-4596. (in Russian, with English summary)

112. Hull, D.L. The effect of essentialism on taxonomy: Two thousand years of stasis. Brit. J. Phil. Sci. 1965, 15, 314-326, DOI:10.1093/bjps/XV.60.314.

113. Ellis, B. Scientific essentialism. Cambridge University Press: Cambridge, GB, 2001; ISBN 978-0-5218-0094-5.

114. Rieppel, O. New essentialism in biology. Phil. Sci. 2010, 77, 662-673, DOI:10.1086/656539.

115. Walsh, D. Evolutionary essentialism. Brit. J. Phil. Sci. 2006, 57. 425-448, DOI: 10.1093/bjps/ax1001.

116. Lewens, T. Evo-devo and "typological thinking": An exculpation. J. Exp. Zool. 2009, 312B, 789-796, DOI:10.1002/jez.b.21292.

117. Riegner, M.F. Ancestor of the new archetypal biology: Goethe's dynamic typology as a model for contemporary evolutionary developmental biology. Stud. Hist. Philos. Biol. Biomed. Sci. 2013, 44, 735-744, DOI:10.1016/j.shpsc.2013.05.019.

118. Vasil'eva, L.N. Hierarchical model of evolution. Zh. Obshch. Biol. 1998, 59, 5-23, ISSN 0044-4596. (in Russian, with English summary) 
119. Waddington, C.H. New pattern in genetics and development. Columbia University Press: New York, NY, USA, 1962; ISBN 978-1-1252-7834-5.

120. Waddington, C.H. Towards a theoretical biology: Prolegomena. Edinburgh University Press: Edinburgh, BG, 1968; ISBN 978-0-8522-4018-2.

121. Meyen, S.V. Plant morphology in its nomothetical aspects. Bot. Rev. 1973, 39, 205-260, https://www.jstor.org/stable/4353853.

122. Slack, J.M.W.; Holland, P.W.H.; Graham, C.F. The zootype and the phylotypic stage. Nature 1993, 361, 490-492, DOI:10.1038/361490a0.

123. Hall, B.K. Baupläne, phylotypic stages, and constraint: why there are so few types of animals. Evol. Biol. 1996, 29, 251-261, https://www.researchgate.net/publication/299347792_Bauplane_phylotypic_stages_and_constr aint_Why_are_there_so_few_types_of_animals/references.

124. Richardson, M.K.; Minelli, A.; Coates, M.; Hanken, J. Phylotypic stage theory. Trends Ecol. Evol. 1998, 13, 158, DOI:10.1016/S0169-5347(98)01340-8.

125. Faith, D.P. 2003. Biodiversity. The Stanford Encyclopedia of Philosophy, Summer 2003 ed.; Zalta, E.N., Ed.; http://plato. stanford.edu/archives/sum2003/entries/biodiversity/.

126. Pavlinov, I.Ya. On the structure of biodiversity: Some metaphysical essays. In Focus on biodiversity research; Schwartz, J., Ed.; Nova Science Publishers: New York, NY, USA, 2007; pp. 101-114, ISBN 978-1-6002-1372-4.

127. Pavlinov, I.Ya. Comments on biomorphics (ecomorphological systematics). Zh. Obshch. Biol. 2010, 71, 187-192, ISSN 0044-4596. (in Russian, with English summary)

128. Warming, E. Om planterigest lifsformer. Festskr. udg. University Kjobenhavn: Kjobenhavn, DK, 1908.

129. Friederichs, F.C. Die Grundfragen und Gesetzmässigkeiten der land- und forstwirtschaftlichen Zoologie, insbesondere der Entomologie. Parey: Berlin, DE, 1930.

130. Ale'ev, Yu.G. Ecomorphology. Naukova Dumka: Kiev, UA, 1986. (in Russian)

131. Leont'ev, D.V.; Akulov, A.Yu. Ecomorphema of the organic world: an experience of construing. Zh. Obshch. Biol. 2004, 65, 500-526, http://ekhnuir.univer.kharkov.ua/bitstream/123456789/5101/2/ecomorphema_2004.pdf. （in Russian, with English summary)

132. Bock, W.J. Concepts and methods in ecomorphology. J. Biosci. 1994, 19, 403-413, DOI:10.1007/BF02703177.

133. Kirpotin, S.N. Life forms of organisms as patterns of organization and spatial environmental factors. Zh. Obshch. Biol. 2005, 66, 239-250, ISSN 0044-4596. (in Russian, with English summary)

134. Du Rietz, G.E. Life forms of terrestrial flowering plants. Acta Phytogeogr. Suec. 1931, 3, 1-95.

135. Remane, A. Die Bedeutung der Lebensformtypen für die Orologi. Biol. Gen. 1943, 17, 164-182.

136. Serebryakov, I.G. Ecological morphology of plants. Life forms of angiosperms and conifers. Vys'shaya Shkola: Moscow, RF, 1962. (in Russian)

137. Mirkin, B.M. Theoretical foundations of contemporary phytocenology. Nauka, Moscow, RF, 1985.

138. Camp, W.H. Biosystematy. Brittonia 1951, 7, 113-127.

139. Hall, H.M.; Clements, F.E. The phylogenetic method in taxonomy: the North American species of Artemisia, Chrysothamnus, and Atriplex. Publ. Carnegie Inst. Wash. 1923, 326, 5-355.

140. Mayr, E.; Bock, W.J. Classifications and other ordering systems. J. Zool. Syst. Evol. Res. 2002, 40, 169-194, DOI:10.1046/j.1439-0469.2002.00211.x.

141. Komarov, V.L. Species and its subdivisions. Dnevnik 11 S'ezda Russ. Estestvoisp. Vrach. 1902, 6, 250-252.

142. Turrill, W.B. Species. J. Bot. Lond. 1925, 63, 359-366.

143. Huxley, J., Ed. The new systematics. Oxford University Press: London, GB, 1940.

144. Mayr, E. Systematics and the origin of species, from the viewpoint of zoologist. Columbia University Press: New York, NY, USA, 1942.

145. Mayr, E. Principles of systematic zoology. McGrow Hill Book Co: New York, NY, USA, 1969; ISBN 978-0-0704-1143-2. 
146. Hubbs, C.L. Racial and individual variation in animals, especially fishes. Amer. Natur. 1934, 68, 115-128, DOI:10.1086/280531.

147. Turrill, W.B. The expansion of taxonomy with special reference to spermatophyta. Biol. Rev. 1938, 13, 342-373, DOI:10.1111/j.1469-185X.1938.tb00522.x.

148. Huxley, J.S. Evolution: The modern synthesis. G. Allen \& Unwin Ltd.: London, GB, 1942.

149. Turreson, G. The species and the varieties as ecological units. Hereditas 1922, 3, 100-113, DOI:10.1111/j.1601-5223.1922.tb02727.x.

150. Sylvester-Bradley, P.C. The classification and coordination of infraspecific categories. Systematic Association: London, GB, 1952.

151. Valentine, D.H.; Löve, A. Taxonomic and biosystematic categories. Brittonia 1958, 10, 153-166, DOI:10.2307/2804945.

152. Huxley, J.S. Clines: an auxiliary method in taxonomy. Bijdr. Dierk. 1939, 27, 491-520, DOI:10.1038/142219a0.

153. Endler, J.A. Geographic variation, speciation and clines. Princeton University Press: Princeton, New Jersey, NJ, USA, 1977; ISBN 978-0-6910-8192-2.

154. Heslop-Harrison, J. New concepts in flowering-plant taxonomy. Harvard University Press: Cambridge, MA, USA, 1960; ISBN 978-0-4356-1390-7.

155. Hoch, P.C.; Stephenson, A.G.; Eds. Experimental and molecular approaches to plant biosystematics. Missouri Botanical Garden: St. Louis, IL, USA, 1995; ISBN 978-0-9152-7930-2.

156. Davis, P.H.; Heywood, V.H. Principles of Angiosperm taxonomy. Oliver \& Boyd: London, GB, 1963; ISBN 978-8-1701-9383-8.

157. Solbrig, O.T. Principles and methods of plant biosystematics. Macmillan Co: New York, NY, USA, 1970; ISBN 978-0-0241-3700-5.

158. Takhtajan A.L. Biosystematics: past, present and future. Bot. Zh. 1970, 55, 331-345. (in Russian)

159. Lines, J.L.; Mertens, T.R. Principles of biosystematics. Educational methods: Chicago, IL, USA, 1970; ISBN 978-1-6828-6265-0.

160. Stace, C.A. Plant taxonomy and biosystematics, $2 \mathrm{~d}$ ed. Cambridge University Press: London, GB, 1989; ISBN 978-0-5214-2785-2.

161. Stuessy, T.F. Plant taxonomy. The systematic evaluation of comparative data, $2 \mathrm{~d}$ ed. Columbia University Press: New York, NY, USA, 2008; ISBN 978-0-2311-4712-5.

162. Mayr, E.; Ashlock, P. Principles of systematic zoology, 2nd ed. McGrow Hill Book Co: New York, NY, USA, 1991; ISBN 978-0-0704-1144-9.

163. Avise, J.C. Phylogeography. The history and formation of species. Harvard University Press: Cambridge, MA, USA, 2000; ISBN 978-0-6746-6638-2.

164. Avise, J.C. Phylogeography: retrospect and prospect. J. Biogeogr. 2009, 36, 3-15, DOI:10.1111/j.1365-2699.2008.02032.x.

165. Gutiérrez-García, T.A.; Vázquez-Domínguez, E. Comparative phylogeography: Designing studies while surviving the process. BioScience 2011, 61, 857-868, DOI:10.1525/bio.2011.61.11.5.

166. Dayrat, B. Towards integrative taxonomy. Biol. J. Linn. Soc. Lond. 2005, 85, 407-415, DOI:10.1111/j.1095-8312.2005.00503.x.

167. Padial, J.M.; Miralles, A.; Riva, I.; Vences, M. The integrative future of taxonomy. Front. Zool. 2010, 7, 16, DOI: 10.1186/1742-9994-7-16.

168. Schlick-Steiner, B.C.; Steiner, F.M.; Seifert, B.; Stauffer, C.; Erhard, C.; Ross, H.C. Integrative taxonomy: A multisource approach to exploring biodiversity. Ann. Rev. Entomol. 2010, 55, 421-438, DOI:10.1146/annurev-ento-112408-085432.

169. Goulding, T.C.; Dayrat, B. Integrative taxonomy: Ten years of practice and looking into the future. In Aspects of biodiversity; Pavlinov, I.Ya., Kalyakin, M.V., Sysoev, A.V., Eds; KMK Sci. Press: Moscow, RF, 2016; pp. 116-133, ISBN 978-5-9908-4166-6.

170. Wiley, E.O. Phylogenetics: the theory and practice of phylogenetic systematics. John Wiley \& Sons: New York, NY, USA, 1981; ISBN 978-0-4710-5975-2.

171. Pavlinov, I.Ya. Introduction to contemporary phylogenetics. KMK Scientific Press. Moscow, RF, 2005; ISBN 978-5-0411-5481-3. (in Russian, with English summary) 
172. Wägele, J.-W. Foundations of phylogenetic systematics. Friedrich Pfeil Verlag: Munchen, DE, 2005; ISBN 978-3-8993-7056-0.

173. Tatarinov L.P. Classification and phylogeny. Zh. Obshch. Biol. 1977, 38, 676-689, ISSN 0044-4596. (in Russian, with English summary)

174. Saether, O.A. Underlying synapomorphies and anagenetic analysis. Zool. Script. 1979, 8, 305-312, DOI:10.1111/j.1463-6409.1979.tb00644.x.

175. Rasnitsyn, A.P. Conceptual issues in phylogeny, taxonomy, and nomenclature. Contribut. Zool. 1996, 66, 3-41, DOI:10.1163/26660644-06601001.

176. Rieppel, O. Monophyly, paraphyly, and natural kinds. Biol. Philos. 2005, 20, 465-487, DOI:10.1007/s10539-004-0679-z.

177. Hörandl, E. Paraphyletic versus monophyletic taxa-evolutionary versus cladistic classification. Taxon 2006, 55, 564-570, DOI:10.2307/25065631.

178. Stuessy, T.F.; Hörandl, E. Evolutionary systematics and paraphyly: Introduction. Ann. Missouri Bot. Gard. 2014, 100, 2-5, DOI:10.3417/2012083.

179. Simpson, G.G. Principles of animal taxonomy. Columbia University Press: New York, NY, USA, 1961; ISBN 978-0-2310-2427-3.

180. Van Valen, L.M. Adaptive zones and the orders of mammals. Evolution 1971, 25, 420-428, DOI:10.2307/2406935.

181. Bock, W. Philosophical foundations of classical evolutionary classification. Syst. Zool. 1974, 11, 375-392, DOI:10.2307/2412945.

182. Bock, W.J. Foundations and methods of evolutionary classification. In Major patterns of vertebrate evolution; Hecht, M.K., Goody, P.C., Hecht, B.M., Eds; Plenum Press New York, NY, USA, 1977; pp. 851-895, ISBN 978-0-3063-5614-8.

183. Zimmermann, W. Arbeitsweise der botanischen Phylogenetik und anderer Gruppierungswissenschaften. In Handbuch der biologischen Arbeitsmethoden; Abderhalden, E., Hrsg., Abt. 3, 1 (9); Urban \& Schwarzenberg: Berlin, DE, 1931.

184. Zimmermann, W. Die Methoden der Phylogenetik. In Die Evolution der Organismen; Heberer, G., Hrsg.; G. Fischer: Jena, DE, 1943, pp. 20-56.

185. Hennig, W. Grundzuge einiger Theorie der phylogenetische Systematik. Deutscher Zentralverlag: Berlin, DE, 1950.

186. Hennig, W. Phylogenetic systematics. University Illinois Press: Urbana, IL, USA, 1966; ISBN 978-0-2520-6814-0.

187. Hamilton, A., Ed. The evolution of phylogenetic systematics. University of California Press: Berkley, CA, USA, 2014; ISBN 978-0-5202-7658-1.

188. Rieppel, O. Phylogenetic systematics. Haeckel to Hennig. Taylor \& Francis: Boca Raton, FL, USA, 2016; ISBN 978-0-3678-7645-6.

189. Shatalkin, A.I. Biological systematics. Moscow University Press: Moscow, RF, 1988; ISBN 978-5-2110-0145-9.

190. Schuh, R.T. Biological systematics. Principles and applications. Cornell University Press: Ithaca, NY, USA, 2000; ISBN 978-0-8014-4799-0.

191. Williams, D.M.; Ebach, M.C. Foundations of systematics and biogeography. Springer Science+Business Media: New York, NY, USA, 2008; ISBN 978-1-4419-4445-0.

192. Mayr, E. Cladistic analysis or cladistic classification? Zeitschr. Zool. Syst. Evol.-forsch. 1974, 12, 94-128, DOI:10.1111/j.1439-0469.1974.tb00160.x.

193. Pavlinov, I.Ya. Cladistic analysis (methodological problems). Moscow University Press: Moscow, RF, 1990; ISBN 5-211-00918-5. (in Russian)

194. Vasil'ev N.A. Imaginary logic. Nauka: Moscow, RF, 1989. (in Russian)

195. Bazhanov, V.A. N.A. Vasil'ev and his imaginary logic. Resurrection of one forgotten idea. Canon+: Moscow, RF, 2009; ISBN 978-5-8837-3196-8. (in Russian, with English summary)

196. Løvtrup, S. Phylogenetics: some comments on cladistic theory and methods. In Major patterns of vertebrate evolution; Hecht, M.K., Goody, P.C., Hecht, B.M., Eds.; Plenum Press: New York, NY, USA, 1977; pp. 805-822, ISBN 978-0-3063-5614-8. 
197. de Queiroz, K.; Gauthier, J. Phylogenetic taxonomy. Annu. Rev. Ecol. Evol. Syst. 1992, 23, 449-480, DOI:10.1146/annurev.es.23.110192.002313.

198. Mishler, B.D.; Wilkins J.S. The hunting of the SNaRC: A snarky solution to the species problem. Philos. Theor. Pract. Biol. 2018, 10, 1-18, DOI:10.3998/ptpbio.16039257.0010.001.

199. Ratner, V.A.; Zharkikh, A.A.; Kolchanov, N.; Rodin, S.N.; Solovyov, V.V.; Antonov, A.S. Molecular Evolution. Springer: Berlin \& Heidelberg, DE, 1996; ISBN 978-3-5405-7083-7.

200. Antonov, A.S. Plant genosystematics. Akademkniga: Moscow, RF, 2006; ISBN 5-9462-8271-9. (in Russian, with English summary)

201. Cracraft, J.; Donoghue, M.J.; Eds. Assembling tree of life. Oxford University Press: Oxford, GB, 2004; ISBN 978-0-1951-7234-8.

202. Bapteste, E.; O’Malley, M.A.; Beiko, R.G.; Ereshefsky, M.; Gogarten, P.; Franklin-Hall, L.; Lapointe, F.-J.; Dupré, J.; Dagan, T.; Boucher, Y. Prokaryotic evolution and the tree of life are two different things. Biol. Direct. 2009, 4, 34, DOI:10.1186/1745-6150-4-34.

203. Wheeler, Q.D., Ed. The new taxonomy. CRC Press: Boca Raton, FL, USA, 2008; ISBN 978-0-8493-9088-3.

204. Williams, D.M.; Knapp, S.; Eds. Beyond cladistics: The branching of a paradigm. University California Press: Berkeley, CA, USA, 2010; ISBN 978-0-5202-6772-5.

205. Hörandl, E. Beyond cladistics: Extending evolutionary classifications into deeper time levels. Taxon 2010, 59, 345-350, DOI:10.2307/25677594.

206. Minelli, A. Phylo-evo-devo: Combining phylogenetics with evolutionary developmental biology. BMC Biol. 2009, 7, 36, DOI:10.1186/1741-7007-7-36.

207. Minelli, A. Biological systematics in the evo-devo era. Europ. J. Taxon. 2015, 125, 1-23, DOI:10.5852/ejt.2015.125.

208. Minelli, A. The development of animal form: Ontogeny, morphology, and evolution. Cambridge University Press: Cambridge, MA, USA, 2003; ISBN 978-0-5110-7241-3.

209. Carroll, S.B. 2005. Endless forms most beautiful: The new science of evo devo and the making of the animal kingdom. Weidenfeld \& Nicolson: London, GB; ISBN 978-0-297-85094-6.

210. Laubichler, M.D.; Maienschein, J.; Eds. From embryology to evo-devo: A history of developmental evolution. The MIT Press: Cambridge, MA, USA, 2007; ISBN 978-0-2625-1334-0.

211. Minelli, A.; Fusco G.; Eds. 2008. Evolving pathways: Key themes in evolutionary developmental biology. Cambridge University Press: New York, NY, USA. ISBN 978-0-521-88024-4

212. Minelli A.; Pradeu, T.; Eds. Towards a Theory of Development. Oxford University Press: London, GB, 2014; ISBN 978-0-1996-7143-4.

213. Moczek, A.P.; Sears, K.E.; Stollewerk, A.; Wittkopp, P.J.; Diggle, P.; Dworkin, I.; Ledon-Rettig, C.; Matus, D.Q.; Roth, S.; Abouheif, E.; et al. The significance and scope of evolutionary developmental biology: A vision for the 21st century. Evol. Devel. 2015, 17: 198-219, DOI:10.1111/ede.12125.

214. Rieppel, O. Ontogeny, phylogeny, and classification. In Phylogeny and the classification of fossil and Recent organisms; Schmidt-Kittler, N., Willmann, R., Eds.; Verlag Paul Parey: Hamburg, DE, 1989; pp. 63-82, ISBN 978-3-4901-4496-6.

215. Rieppel, O. Ontogeny - a way forward for systematics, a way backward for phylogeny. Biol. J. Linn. Soc. Lond. 2008, 39, 177-191, DOI:10.1111/j.1095-8312.1990.tb00510.x.

216. Garey, M.R.; Johnson, D.S. Computer and intractability: A guide to the theory of NP-completeness. W.H. Freeman \& Co: San Francisco, CA, USA, 1979; ISBN 978-0-7167-1045-5.

217. Babbitt, C.C. 2005. Developmental systematics: Synthesizing ontogeny and phylogeny in the Malacostraca (Crustacea). PhD. Dissert. University of Chicago: Ann Arbor; https://www.researchgate.net/publication/35700543_Developmental_systematics_synthesizing _ontogeny_and_phylogeny_in_the_malacostraca_crustacea

218. Martynov, A.; Ishida, Y.; Irimura, S.; Tajiri, R.; O’Hara, T.; Fujita, T. When ontogeny matters: A new Japanese species of brittle star illustrates the importance of considering both adult and juvenile characters in taxonomic practice. PLoS ONE 2015, 10, e0139463, DOI:10.1371/journal.pone.0139463.

219. Ereshefsky, M. Eliminative pluralism. Phil. Sci. 1992, 59, 671-690, DOI:10.1086/289701. 
220. Minelli, A. Taxonomy needs pluralism, but a controlled and manageable one. Megataxa 2020, 1: 9-18, DOI:10.11646/megataxa.1.1.3.

221. Garnett, S.T.; Christidis, L. Taxonomy anarchy hampers conservation. Nature 2017, 546, 25-27, DOI:10.1038/546025a.

222. Raposo, M.A.; Stopiglia, R.; Brito, G.R.R.; Bockmann, F.A.; Kirwan, G.M.; Gayon, J.; Dubois, A. What really hampers taxonomy and conservation? A riposte to Garnettand Christidis (2017). Zootaxa 2017, 4317, 179-184, DOI: 10.11646/zootaxa.4317.1.10.

223. Thomson, S.A.; Pyle, R.L.; Ahyong, S.T.; Alonso-Zarazaga, M.; Ammirati, J.; Araya J.F.; Ascher, J.S., Audisio, T.L.; Azevedo-Santos, V.M.; Bailly, N.; et al. Taxonomy based on science is necessary for global conservation PLoS Biol. 2018, 16, e2005075, DOI: 10.1371/journal.pbio.2005075.

224. Khaitun, S.D. The crisis of science as a mirror reflection of the crisis of the theory of knowledge. LENAND: Moscw, RF, 2014; ISBN 978-5-9710-2665-5.

225. Broughton, $\mathrm{V}$. The need for a faceted classification as the basis of all methods of information retrieval. New Inform. Persp. 2006, 58, 49-72, DOI:10.1108/00012530610648671. 